\title{
Jet Impingement Heat Transfer: Physics, Correlations, and Numerical Modeling
}

\author{
N. ZUCKERMAN and N. LIOR \\ Department of Mechanical Engineering and Applied Mechanics, The University of Pennsylvania, \\ Philadelphia,PA,USA; E-mail: zuckermn@seas.upenn.edu; lior@seas.upenn.edu
}

\section{Summary}

The applications, physics of the flow and heat transfer phenomena, available empirical correlations and values they predict, and numerical simulation techniques and results of impinging jet devices for heat transfer are described. The relative strengths and drawbacks of the $k-\varepsilon, k-\omega$, Reynolds stress model, algebraic stress models, shear stress transport, and $v^{2} f$ turbulence models for impinging jet flow and heat transfer are compared. Select model equations are provided as well as quantitative assessments of model errors and judgments of model suitability.

\section{Introduction}

We seek to understand the flow field and mechanisms of impinging jets with the goal of identifying preferred methods of predicting jet performance. Impinging jets provide an effective and flexible way to transfer energy or mass in industrial applications. A directed liquid or gaseous flow released against a surface can efficiently transfer large amounts of thermal energy or mass between the surface and the fluid. Heat transfer applications include cooling of stock material during material forming processes, heat treatment [1], cooling of electronic components, heating of optical surfaces for defogging, cooling of turbine components, cooling of critical machinery structures, and many other industrial processes. Typical mass transfer applications include drying and removal of small surface particulates. Abrasion and heat transfer by impingement are also studied as side effects of vertical/short take-off and landing jet devices, for example in the case of direct lift propulsion systems in vertical/short take-off and landing aircraft. 
General uses and performance of impinging jets have been discussed in a number of reviews [2-5].

In the example of turbine cooling applications [6], impinging jet flows may be used to cool several different sections of the engine such as the combustor case (combustor can walls), turbine case/liner, and the critical hightemperature turbine blades. The gas turbine compressor offers a steady flow of pressurized air at temperatures lower than those of the turbine and of the hot gases flowing around it. The blades are cooled using pressurized bleed flow, typically available at $600^{\circ} \mathrm{C}$. The bleed air must cool a turbine immersed in gas of $1400^{\circ} \mathrm{C}$ total temperature [7], which requires transfer coefficients in the range of $1000-3000 \mathrm{~W} / \mathrm{m}^{2} \mathrm{~K}$. This equates to a heat flux on the order of $1 \mathrm{MW} / \mathrm{m}^{2}$. The ability to cool these components in high-temperature regions allows higher cycle temperature ratios and higher efficiency, improving fuel economy, and raising turbine power output per unit weight. Modern turbines have gas temperatures in the main turbine flow in excess of the temperature limits of the materials used for the blades, meaning that the structural strength and component life are dependent upon effective cooling flow. Compressor bleed flow is commonly used to cool the turbine blades by routing it through internal passages to keep the blades at an acceptably low temperature. The same air can be routed to a perforated internal wall to form impinging jets directed at the blade exterior wall. Upon exiting the blade, the air may combine with the turbine core airflow. Variations on this design may combine the impinging jet device with internal fins, smooth or roughened cooling passages, and effusion holes for film cooling. The designer may alter the spacing or locations of jet and effusion holes to concentrate the flow in the regions requiring the greatest cooling. Though the use of bleed air carries a performance penalty [8], the small amount of flow extracted has a small influence on bleed air supply pressure and temperature. In addition to highpressure compressor air, turbofan engines provide cooler fan air at lower pressure ratios, which can be routed directly to passages within the turbine liner. A successful design uses the bleed air in an efficient fashion to minimize the bleed flow required for maintaining a necessary cooling rate.

Compared to other heat or mass transfer arrangements that do not employ phase change, the jet impingement device offers efficient use of the fluid, and high transfer rates. For example, compared with conventional convection cooling by confined flow parallel to (under) the cooled surface, jet impingement produces heat transfer coefficients that are up to three times higher at a given maximum flow speed, because the impingement boundary layers are much thinner, and often the spent flow after the impingement serves to turbulate the surrounding fluid. Given a required heat transfer coefficient, the flow required from an impinging jet device may be two orders of magnitude smaller than that required for a cooling approach using 
a free wall-parallel flow. For more uniform coverage over larger surfaces multiple jets may be used. The impingement cooling approach also offers a compact hardware arrangement.

Some disadvantages of impingement cooling devices are: (1) For moving targets with very uneven surfaces, the jet nozzles may have to be located too far from the surface. For jets starting at a large height above the target (over 20 jet nozzle diameters) the decay in kinetic energy of the jet as it travels to the surface may reduce average $N u$ by $20 \%$ or more. (2) The hardware changes necessary for implementing an impinging jet device may degrade structural strength (one reason why impinging jet cooling is more easily applied to turbine stator blades than to rotor blades). (3) In static applications where very uniform surface heat or mass transfer is required, the resulting high density of the jet array and corresponding small jet height may be impractical to construct and implement, and at small spacings jet-tojet interaction may degrade efficiency.

Prior to the design of an impinging jet device, the heat transfer at the target surface is typically characterized by a Nusselt number $(\mathrm{Nu})$, and the mass transfer from the surface with a Schmidt number $(S c)$. For design efficiency studies and device performance assessment, these values are tracked vs. jet flow per unit area $(G)$ or vs. the power required to supply the flow (incremental compressor power).

\section{A. Impinging Jet Regions}

The flow of a submerged impinging jet passes through several distinct regions, as shown in Fig. 1. The jet emerges from a nozzle or opening with a velocity and temperature profile and turbulence characteristics dependent upon the upstream flow. For a pipe-shaped nozzle, also called a tube nozzle or cylindrical nozzle, the flow develops into the parabolic velocity profile common to pipe flow plus a moderate amount of turbulence developed upstream. In contrast, a flow delivered by application of differential pressure across a thin, flat orifice will create an initial flow with a fairly flat velocity profile, less turbulence, and a downstream flow contraction (vena contracta). Typical jet nozzles designs use either a round jet with an axisymmetric flow profile or a slot jet, a long, thin jet with a two-dimensional flow profile.

After it exits the nozzle, the emerging jet may pass through a region where it is sufficiently far from the impingement surface to behave as a free submerged jet. Here, the velocity gradients in the jet create a shearing at the edges of the jet which transfers momentum laterally outward, pulling additional fluid along with the jet and raising the jet mass flow, as shown in Fig. 2. In the process, the jet loses energy and the velocity profile is widened in spatial extent and decreased in magnitude along the sides of the jet. Flow interior to the 


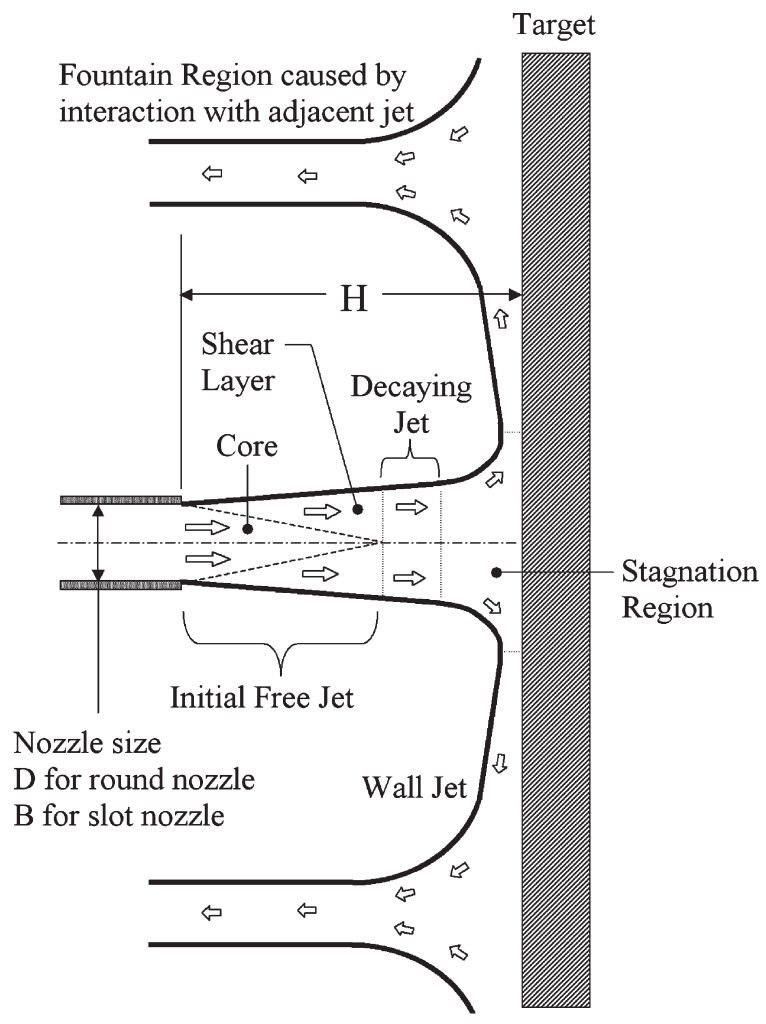

FIG. 1. The flow regions of an impinging jet.

progressively widening shearing layer remains unaffected by this momentum transfer and forms a core region with a higher total pressure, though it may experience a drop in velocity and pressure decay resulting from velocity gradients present at the nozzle exit. A free jet region may not exist if the nozzle lies within a distance of two diameters $(2 D)$ from the target. In such cases, the nozzle is close enough to the elevated static pressure in the stagnation region for this pressure to influence the flow immediately at the nozzle exit.

If the shearing layer expands inward to the center of the jet prior to reaching the target, a region of core decay forms. For purposes of distinct identification, the end of the core region may be defined as the axial position where the centerline flow dynamic pressure (proportional to speed squared) reaches $95 \%$ of its original value. This decaying jet begins four to eight nozzle diameters or slot-widths downstream of the nozzle exit. In the decaying jet, the axial velocity component in the central part decreases, with the radial 


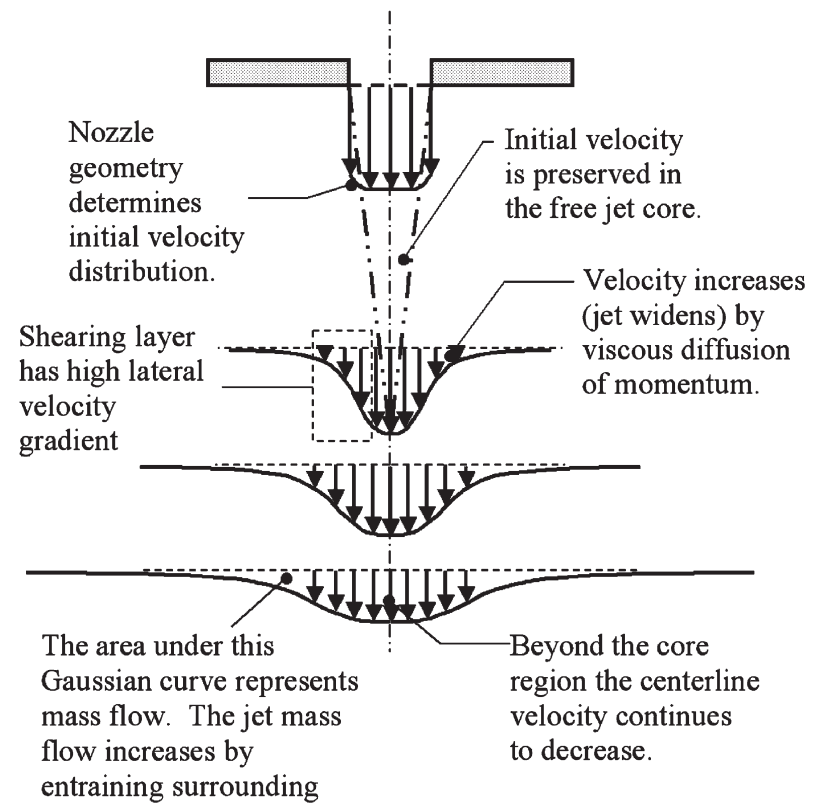

flow.

FIG. 2. The flow field of a free submerged jet.

velocity profile resembling a Gaussian curve that becomes wider and shorter with distance from the nozzle outlet. In this region, the axial velocity and jet width vary linearly with axial position. Martin [2] provided a collection of equations for predicting the velocity in the free jet and decaying jet regions based on low Reynolds number flow. Viskanta [5] further subdivided this region into two zones, the initial "developing zone," and the "fully developed zone" in which the decaying free jet reaches a Gaussian velocity profile.

As the flow approaches the wall, it loses axial velocity and turns. This region is labeled the stagnation region or deceleration region. The flow builds up a higher static pressure on and above the wall, transmitting the effect of the wall upstream. The nonuniform turning flow experiences high normal and shear stresses in the deceleration region, which greatly influence local transport properties. The resulting flow pattern stretches vortices in the flow and increases the turbulence. The stagnation region typically extends 1.2 nozzle diameters above the wall for round jets [2]. Experimental work by Maurel and Solliec [9] found that this impinging zone was characterized or delineated by a negative normal-parallel velocity correlation $(\overline{u v}<0)$. For their slot jet this region extended to $13 \%$ of the nozzle height $H$, and did not vary with $R e$ or $H / D$. 
After turning, the flow enters a wall jet region where the flow moves laterally outward parallel to the wall. The wall jet has a minimum thickness within $0.75-3$ diameters from the jet axis, and then continually thickens moving farther away from the nozzle. This thickness may be evaluated by measuring the height at which wall-parallel flow speed drops to some fraction (e.g. 5\%) of the maximum speed in the wall jet at that radial position. The boundary layer within the wall jet begins in the stagnation region, where it has a typical thickness of no more than $1 \%$ of the jet diameter [2]. The wall jet has a shearing layer influenced by both the velocity gradient with respect to the stationary fluid at the wall (no-slip condition) and the velocity gradient with respect to the fluid outside the wall jet. As the wall jet progresses, it entrains flow and grows in thickness, and its average flow speed decreases as the location of highest flow speed shifts progressively farther from the wall. Due to conservation of momentum, the core of the wall jet may accelerate after the flow turns and as the wall boundary layer develops. For a round jet, mass conservation results in additional deceleration as the jet spreads radially outward.

\section{B. Nondimensional Heat and Mass Transfer Coefficients}

A major parameter for evaluating heat transfer coefficients is the Nusselt number,

$$
N u=h D_{h} / k_{c}
$$

where $h$ is the convective heat transfer coefficient defined as

$$
h=\frac{-k_{c} \partial T / \partial \vec{n}}{T_{0 j e t}-T_{\text {wall }}}
$$

where $\partial T / \partial n$ gives the temperature gradient component normal to the wall.

The selection of Nusselt number to measure the heat transfer describes the physics in terms of fluid properties, making it independent of the target characteristics. The jet temperature used, $T_{0 j e t}$, is the adiabatic wall temperature of the decelerated jet flow, a factor of greater importance at increasing Mach numbers. The non-dimensional recovery factor describes how much kinetic energy is transferred into and retained in thermal form as the jet slows down:

$$
\text { recovery factor }=\frac{T_{w a l l}-T_{0 j e t}}{U_{j e t}^{2} / 2 c_{p}}
$$


This definition may introduce some complications in laboratory work, as a test surface is rarely held at a constant temperature, and more frequently held at a constant heat flux. Experimental work by Goldstein et al. [10] showed that the temperature recovery factor varies from $70 \%$ to $110 \%$ of the full theoretical recovery, with lowered recoveries in the stagnation region of a low- $H / D$ jet $(H / D=2)$, and $100 \%$ elevated stagnation region recoveries for jets with $H / D=6$ and higher. The recovery comes closest to uniformity for intermediate spacings around $H / D=5$. Entrainment of surrounding flow into the jet may also influence jet performance, changing the fluid temperature as it approaches the target.

The nondimensional Sherwood number defines the rate of mass transfer in a similar fashion:

$$
\begin{gathered}
S h=k_{i} D / D_{i} \\
k_{i}=D_{i}[\partial C / \partial n] /\left[C_{0 j e t}-C_{\text {wall }}\right]
\end{gathered}
$$

where $\partial C / \partial n$ gives the mass concentration gradient component normal to the wall.

With sufficiently low mass concentration of the species of interest, the spatial distribution of concentration will form patterns similar to those of the temperature pattern. Studies of impinging air jets frequently use the nondimensional relation:

$$
\mathrm{Nu} / \mathrm{Sh}=(\mathrm{Pr} / \mathrm{Sc})^{0.4}
$$

to relate heat and mass transfer rates.

The nondimensional parameters selected to describe the impinging jet heat transfer problem include the fluid properties such as Prandtl number $\operatorname{Pr}$ (the ratio of fluid thermal diffusivity to viscosity, fairly constant), plus the following:

- $H / D$ : nozzle height to nozzle diameter ratio;

- $r / D$ : nondimensional radial position from the center of the jet;

- $z / D$ : nondimensional vertical position measured from the wall;

- $T u$ : nondimensional turbulence intensity, usually evaluated at the nozzle;

- $R e_{0}$ : Reynolds number $U_{0} D / v$;

- $M$ : Mach number (the flow speed divided by speed of sound in the fluid), based on nozzle exit average velocity (of smaller importance at low speeds, i.e. $M<0.3$;

- $p_{j e t} / D$ : jet center-to-center spacing (pitch) to diameter ratio, for multiple jets; 
- $A_{f}$ : free area ( $=1-[$ total nozzle exit area/total target area]);

- $f$ : relative nozzle area ( $=$ total nozzle exit area/total target area).

The fluid properties are conventionally evaluated using the flow at the nozzle exit as a reference location. Characteristics at the position provide the average flow speed, fluid temperature, viscosity, and length scale $D$. In the case of a slot jet the diameter $D$ is replaced in some studies by slot width $B$, or slot hydraulic diameter $2 B$ in others.

A complete description of the problem also requires knowledge of the velocity profile at the nozzle exit, or equivalent information about the flow upstream of the nozzle, as well as boundary conditions at the exit of the impingement region. Part of the effort of comparing information about jet impingement is to thoroughly know the nature and magnitude of the turbulence in the flow field.

The geometry and flow conditions for the impinging jet depend upon the nature of the target and the fluid source (compressor or blower). In cases where the pressure drop associated with delivering and exhausting the flow is negligible, the design goal is to extract as much cooling as possible from a given air mass flow. Turbine blade passage cooling is an example of such an application; engine compressor air is available at a pressure sufficient to choke the flow at the nozzle (or perhaps at some other point in the flow path). As the bleed flow is a small fraction of the overall compressor flow, the impinging jet nozzle pressure ratio varies very little with changes in the amount of airflow extracted. At high pressure ratios the jet emerges at a high Mach number. In the most extreme case, the flow exits the nozzle as an underexpanded supersonic jet. This jet forms complex interacting shock patterns and a stagnation or recirculation "bubble" directly below the jet (shown in Fig. 3), which may degrade heat transfer [11].

The details of the impingement device design affect the system pressure drop and thus the overall device performance. In the case of a device

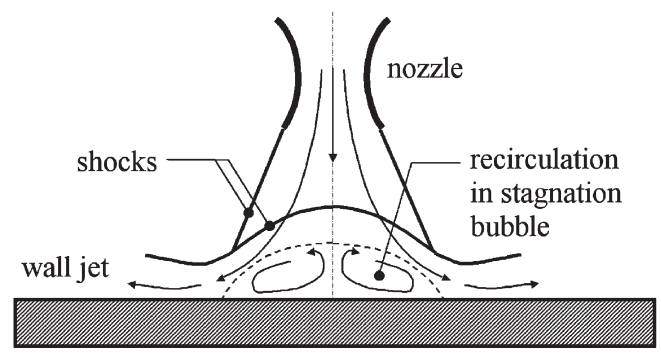

Fig. 3. Supersonic jet flow pattern. 
powered by a blower or compressor, the blower power draw can be predicted using the required pressure rise, flow, and blower efficiency including any losses in the motor or transmission. For incompressible duct flow one can then estimate the power by multiplying the blower pressure rise $\Delta p$ by the volumetric flow $Q$ and then dividing by one or more efficiency factors (e.g., using a total efficiency of 0.52 based on a 0.65 blower aerodynamic efficiency times 0.80 motor efficiency). This same approach works for calculating pump power when dealing with liquid jets, but becomes more complex when dealing with a turbine-cooling problem where compressibility is significant.

The blower pressure rise $\Delta p$ depends on the total of the pressure losses in the blower intake pathway, losses in the flow path leading to the nozzle, any total pressure loss due to jet confinement and jet interaction, and any losses exiting the target region. In cases where space is not critical the intake pathway and nozzle supply pathway are relatively open, for there is no need to accelerate the flow far upstream of the nozzle exit. When possible, the flow is maintained at low speed (relative to $U_{j e t}$ ) until it nears the nozzle exit, and then accelerated to the required jet velocity by use of a smoothly contracting nozzle at the end of a wide duct or pipe. In such a case, the majority of the loss occurs at the nozzle where the dynamic pressure is greatest. For a cylindrical nozzle, this loss will be at least equal to the nozzle dump loss, giving a minimum power requirement of $\left(0.5 \rho U_{\text {jet }}^{2} Q\right)$.

Jet impingement devices have pressure losses from the other portions of the flow path, and part of the task of improving overall device performance is to reduce these other losses. For this reason, one or more long, narrow supply pipes (common in experimental studies) may not make an efficient device due to high frictional losses approaching the nozzle exit. When orifice plate nozzles are used the upstream losses are usually small, but the orifices can cause up to 2.5 times the pressure drop of short, smooth pipe nozzles (at a set $Q$ and $D$ ). This effect is balanced against the orifice nozzle's larger shear layer velocity gradient and more rapid increase in turbulence in the free-jet region [12]. Such orifice plates take up a small volume for the hardware, and are relatively easy and inexpensive to make. A thicker orifice plate (thickness from $0.3 D$ to $1.5 D$ ) allows the making of orifice holes with tapered or rounded entry pathways, similar to the conical and bellmouth shapes used in contoured nozzles. This compromise comes at the expense of greater hardware volume and complexity, but reduces the losses associated with accelerating the flow as it approaches the orifice and increases the orifice discharge coefficient (effective area). Calculation of nozzle pressure loss may use simple handbook equations for a cylindrical nozzle [13,14], but for an orifice plate the calculations may require more specialized equations and test data (cf. $[15,16])$. 
TABLE I

Comparison of Nozzle-Type Characteristics

\begin{tabular}{lcccl}
\hline Nozzle type & $\begin{array}{c}\text { Initial } \\
\text { turbulence }\end{array}$ & $\begin{array}{c}\text { Free jet } \\
\text { shearing force }\end{array}$ & $\begin{array}{c}\text { Pressure } \\
\text { drop }\end{array}$ & $\begin{array}{c}\text { Nozzle exit velocity } \\
\text { profile }\end{array}$ \\
\hline Pipe & High & Low & High & Close to parabolic \\
$\begin{array}{c}\text { Contoured } \\
\text { contraction }\end{array}$ & Low & $\begin{array}{c}\text { Moderate to } \\
\text { high }\end{array}$ & Low & Uniform (flat) \\
Sharp orifice & Low & High & High & $\begin{array}{c}\text { Close to uniform } \\
\text { (contracting) }\end{array}$ \\
\hline
\end{tabular}

Table I compares characteristics of the most common nozzle geometries in a qualitative fashion.

\section{Turbulence Generation and Effects}

Jet behavior is typically categorized and correlated by its Reynolds number $R e=U_{0} D / v$, defined using initial average flow speed $\left(U_{0}\right)$, the fluid viscosity $(v)$ and the characteristic length that is the nozzle exit diameter $D$ or twice the slot width, $2 B$ (the slot jet hydraulic diameter). At $R e<1000$ the flow field exhibits laminar flow properties. At $R e>3000$ the flow has fully turbulent features. A transition region occurs with $1000<R e<3000$ [5]. Turbulence has a large effect on the heat and mass transfer rates. Fully laminar jets are amenable to analytical solution, but such jets provide less heat transfer at a given flow rate than turbulent ones, and therefore much more literature exists for turbulent impinging jets.

For example, an isolated round jet at $R e=2000$ (transition to turbulence), $\operatorname{Pr}=0.7, H / D=6$ will deliver an average $N u$ of 19 over a circular target spanning six jet diameters, while at $R e=100,000$ the average $N u$ on the same target will reach 212 [2]. In contrast, laminar jets at close target spacing will give $N u$ values in the range of $2-20$. In general, the exponent $b$ in the relationship $N u \propto R e^{b}$ ranges from $b=0.5$ for low-speed flows with a low-turbulence wall jet, up to $b=0.85$ for high $R e$ flows with a turbulence-dominated wall jet. As an example of the possible extremes, Rahimi et al. [17] measured local $N u$ values as high as 1700 for a underexpanded supersonic jet at $\operatorname{Re}=(1.028) \times 10^{6}$.

Typical gas jet installations for heat transfer span a Reynolds number range from 4000 to 80,000 . $H / D$ typically ranges from 2 to 12 . Ideally, $\mathrm{Nu}$ increases as $H$ decreases, so a designer would prefer to select the smallest tolerable $H$ value, noting the effects of exiting flow, manufacturing 
capabilities, and physical constraints, and then select nozzle size $D$ accordingly. For small-scale turbomachinery applications jet arrays commonly have $D$ values of $0.2-2 \mathrm{~mm}$, while for larger scale industrial applications, jet diameters are commonly in the range of $5-30 \mathrm{~mm}$. The diameter is heavily influenced by manufacturing and assembly capabilities.

Modeling of the turbulent flow, incompressible except for the cases where the Mach number is high, is based on using the well-established mass, momentum, and energy conservation equations based on the velocity, pressure, and temperature:

$$
\begin{gathered}
\frac{\partial \overline{u_{i}}}{\partial x_{i}}=0 \\
\rho \frac{\partial \overline{u_{i}}}{\partial t}+\rho \overline{u_{i}} \frac{\partial \overline{u_{j}}}{\partial x_{j}}=-\frac{\partial \bar{p}}{\partial x_{i}}+\frac{\partial \sigma_{i j}}{\partial x_{j}}+\frac{\partial \tau_{i j}}{\partial x_{j}} \\
\rho \frac{\partial \overline{u_{i}}}{\partial t}+\rho \overline{u_{i}} \frac{\partial \overline{u_{j}}}{\partial x_{j}}=-\frac{\partial \bar{p}}{\partial x_{i}}+\frac{\partial}{\partial x_{j}}\left[\mu\left(\frac{\partial \overline{u_{i}}}{\partial x_{j}}+\frac{\partial \overline{u_{j}}}{\partial x_{i}}\right)\right] \\
+\frac{\partial}{\partial x_{j}}\left(-\rho \overline{u_{i}^{\prime} u_{j}^{\prime}}\right)(\text { alternate form }) \\
\frac{\partial \bar{T}}{\partial t}+\rho c_{p} \overline{u_{j}} \frac{\partial \bar{T}}{\partial x_{j}}=\sigma_{i j} \frac{\partial \bar{u}_{i}}{\partial x_{j}}+\frac{\partial}{\partial x_{j}}\left(\frac{\mu c_{p}}{P r} \frac{\partial \bar{T}}{\partial x_{j}}\right)+\frac{\partial}{\partial x_{j}}\left(-\rho c_{p} \overline{u_{j}^{\prime} T^{\prime}}\right) \\
+\mu\left(\frac{\partial u_{i}^{\prime}}{\partial x_{j}}+\frac{\partial u_{j}^{\prime}}{\partial x_{i}}\right) \frac{\partial u_{i}^{\prime}}{\partial x_{j}} \\
\sigma_{i j}=\mu\left(\frac{\partial \overline{u_{i}}}{\partial x_{j}}+\frac{\partial \overline{u_{j}}}{\partial x_{i}}\right) \\
\tau_{i j}=-\rho \overline{u_{i}^{\prime} u_{j}^{\prime}}
\end{gathered}
$$

where an overbar above a single letter represents a time-averaged term, terms with a prime symbol $(')$ represent fluctuating values, and a large overbar represents a correlation.

The second moment of the time variant momentum equation, adjusted to extract the fluctuating portion of the flow field, yields the conservative transport equation for Reynolds stresses, shown for an incompressible 
fluid [18]:

$$
\begin{aligned}
\frac{\partial \tau_{i j}}{\partial t}+\bar{u}_{k} \frac{\partial \tau_{i j}}{\partial x_{k}}= & {\left[-\tau_{i k} \frac{\partial \bar{u}_{j}}{\partial x_{k}}-\tau_{j k} \frac{\partial \bar{u}_{i}}{\partial x_{k}}\right]+\left[\overline{\frac{p^{\prime}}{\rho}\left(\frac{\partial u_{i}^{\prime}}{\partial x_{j}}+\frac{\partial u_{j}^{\prime}}{\partial x_{i}}\right)}\right] } \\
& +\left[\frac{\partial}{\partial x_{k}}\left(-\overline{u_{i}^{\prime} u_{j}^{\prime} u_{k}^{\prime}}-\frac{\overline{p^{\prime}}}{\rho}\left\{\overline{\left.u_{i}^{\prime} \delta_{j k}+u_{j}^{\prime} \delta_{i k}\right\}}\right)\right]\right. \\
& +\left[-2 v \frac{\partial u_{i}^{\prime}}{\partial x_{k}} \frac{\partial u_{j}^{\prime}}{\partial x_{k}}\right]+\left[v \frac{\partial^{2} \tau_{i j}}{\partial x_{k} \partial x_{k}}\right]
\end{aligned}
$$

Each term of this equation has a specific significance.

- The term $\frac{\partial \tau_{i j}}{\partial t}+\bar{u}_{k} \frac{\partial \tau_{i j}}{\partial x_{k}}$ represents convective transport of Reynolds stresses.

- The term $-\tau_{i k} \frac{\partial \bar{u}_{j}}{\partial x_{k}}-\tau_{j k} \frac{\partial \bar{u}_{i}}{\partial x_{k}}$ measures turbulent production of Reynolds stresses.

- The term $\overline{\frac{p^{\prime}}{\rho}\left(\frac{\partial u_{i}^{\prime}}{\partial x_{j}}+\frac{\partial u_{j}^{\prime}}{\partial x_{i}}\right)}$ measures the contribution of the pressure-strain rate correlation to Reynolds stresses.

- The term $\frac{\partial}{\partial x_{k}}\left(-\overline{u_{i}^{\prime} u_{j}^{\prime} u_{k}^{\prime}}-\overline{\frac{p^{\prime}}{\rho}\left\{u_{i}^{\prime} \delta_{j k}+u_{j}^{\prime} \delta_{i k}\right\}}\right)$ gives the effects of the gradient of turbulent diffusion.

- The term $-2 v \frac{\overline{\partial u_{i}^{\prime}} \frac{\partial u_{j}^{\prime}}{\partial x_{k}}}{\partial x_{k}}$ represents the effects of turbulent dissipation.

- The term $v \frac{\partial^{2} \tau_{i j}}{\partial x_{k} \partial x_{k}}$ represents the effects of molecular diffusion.

The specific turbulent kinetic energy $k$, gives a measure of the intensity of the turbulent flow field. This can be nondimensionalized by dividing it by the time-averaged kinetic energy of the flow to give the turbulence intensity, based on a velocity ratio:

$$
T u=\sqrt{\frac{\overline{\bar{u}_{j}^{\prime} u_{j}^{\prime}}}{\bar{u}_{i} \bar{u}_{i}}}
$$

In addition to generation in the impinging jet flow field itself, turbulence in the flow field may also be generated upstream of the nozzle exit and convected into the flow. This often takes place due to the coolant flow distribution configuration, but can also be forced for increasing the heat transfer coefficients, by inserting various screens, tabs, or other obstructions in the jet supply pipe upstream of or at the nozzle. Experimental work has shown that this decreases the length of the jet core region, thus reducing the 
$H / D$ at which the maximal $N u_{\text {avg }}$ is reached [19]. The downstream flow and heat transfer characteristics are sensitive to both the steady time-averaged nozzle velocity profile and fluctuations in the velocity over time. Knowledge of these turbulent fluctuations and the ability to model them, including associated length scales, are vital for understanding and comparing the behavior and performance of impinging jets.

In the initial jet region the primary source of turbulence is the shear flow on the edges of the jet. This shear layer may start as thin as a knife-edge on a sharp nozzle, but naturally grows in area along the axis of the jet. At higher Reynolds numbers, the shear layer generates flow instability, similar to the Kelvin-Helmholtz instability. Figure 4 presents in a qualitative fashion the experimentally observed pattern of motion at the edges of the unstable free jet. At high flow speeds $(R e>1000)$ the destabilizing effects of shear forces may overcome the stabilizing effect of fluid viscosity/momentum diffusion. The position of the shear layer and its velocity profile may develop oscillations in space, seemingly wandering from side to side over time. Further downstream, the magnitude and spatial extent of the oscillations grow to form large-scale eddies along the sides of the jet. The largest eddies have a length scale of the same order of magnitude as the jet diameter and persist until they either independently break up into smaller eddies or meet and interact with other downstream flow features. The pressure field of the stagnation region further stretches and distorts the eddies, displacing them laterally until they arrive at the wall.

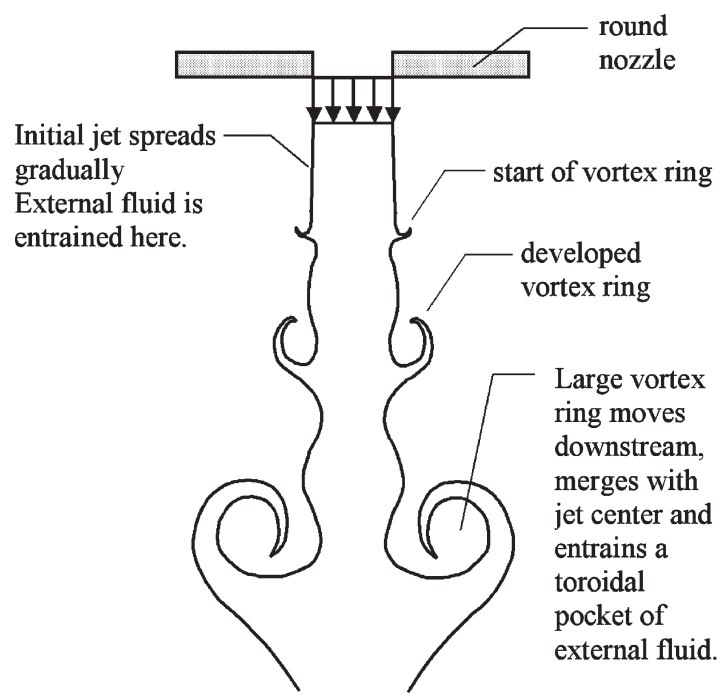

FIG.4. Instability in the turbulent free jet. 
Experiments by Hoogendorn [20] found that the development of turbulence in the free jet affected the profile of the local $N u$ on the target stagnation region as well as the magnitude. For pipe nozzles and for contoured nozzles at high spacing $(z / D>5)$ the $N u$ profiles had a peak directly under the jet axis. For contoured nozzles at $z / D=2$ and 4 with low initial turbulence $(T u \sim 1 \%)$, the maximum $N u$ occurred in the range $0.4<r / D<0.6$ with a local minimum at $r=0$, typically $95 \%$ of the peak value.

In the decaying jet region the shear layer extends throughout the center of the jet. This shearing promotes flow turbulence, but on smaller scales. The flow in the decaying jet may form small eddies and turbulent pockets within the center of the jet, eventually developing into a unstructured turbulent flow field with little or no coherent structures in the entire jet core.

In the deceleration region, additional mechanisms take part in influencing flow field turbulence. The pressure gradients within the flow field cause the flow to turn, influencing the shear layer and turning and stretching largescale structures. The deceleration of the flow creates normal strains and stresses, which promote turbulence. Numerical models by Abe and Suga [21] showed that the transport of heat or mass in this region is dominated by large-scale eddies, in contrast to the developed wall jet where shear strains dominate.

The flow traveling along the wall may make a transition to turbulence in the fashion of a regular parallel wall jet, beginning with a laminar flow boundary layer region and then reaching turbulence at some lateral position on the wall away from the jet axis. For transitional and turbulent jets, the flow approaching the wall already has substantial turbulence. This turbulent flow field may contain large fluctuations in the velocity component normal to the wall, a phenomenon distinctly different than those of wall-parallel shear flows [22].

Large-scale turbulent flow structures in the free jet have a great effect upon transfer coefficients in the stagnation region and wall jet. The vortices formed in the free jet-shearing layer, categorized as primary vortices, may penetrate into the boundary layer and exchange fluids of differing kinetic energy and temperature (or concentration). The ability of the primary vortex to dynamically scrub away the boundary layer as it travels against and along the wall increases the local heat and mass transfer.

The turbulent flow field along the wall may also cause formation of additional vortices categorized as secondary vortices. Turbulent fluctuations in lateral/radial velocity and associated pressure gradient fluctuations can produce local flow reversals along the wall, initiating separation and the formation of the secondary vortices, as shown in Fig. 5. Secondary vortices cause local rises in heat/mass transfer rates and like the primary vortices 


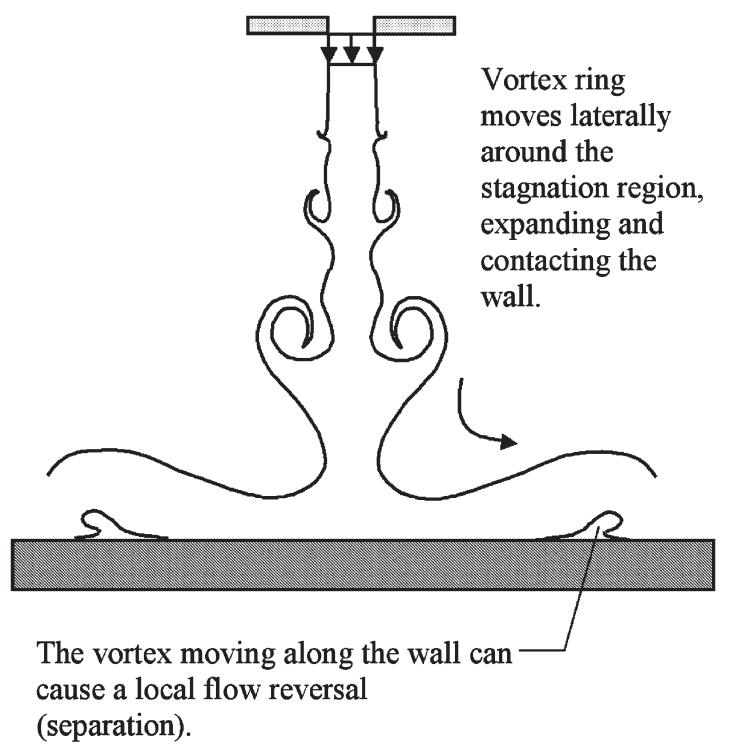

FIG. 5. Vortex motion in the impinging jet.

they result in overall loss of flow kinetic energy and after they disperse downstream may cause local regions of lower transfer rate. Gardon and Akfirat [23] noted a secondary peak in the transfer coefficient and attributed this to boundary layer transition along the wall. More recent studies at various Reynolds numbers concluded that large-scale vortex activity along the wall may generate a secondary peak in transfer coefficients and causes most of the variation in $N u$ over time [24]. Some investigations suggest that the turbulence in this region is generated by increased shear forces in the thin accelerating region immediately outside the stagnation region [25]. Time-averaged numerical modeling by the authors for $H / D=2$ showed that the shear layer in the upper portion of the wall jet generates the majority of turbulence in the flow field. This high-turbulence region grows streamwise and also spreads in the wall-normal direction. The location of the secondary peak coincides with the location of highest turbulent kinetic energy adjacent to the wall. This numerically predicted effect correlates well with the findings of Narayanan et al. [26], who found that maximum $N u$ occurred in regions with high outer wall-jet region turbulence, rather than in regions exhibiting high turbulence only in the near-wall portion of the wall jet. Their specific conclusion was that the outer region turbulence caused an unsteadiness in the thermal boundary layer outside of the stagnation region. 


\section{Jet Geometry}

These flow and turbulence effects, and the heat or mass transfer rates, are strongly influenced by the geometry of the impinging jet device. These include tubes or channels, and orifices (frequently as a perforated flat plate). The use of an enlarged plenum upstream of the orifice (Fig. 6) serves to dampen supply pressure oscillations, to smooth supply velocity and temperature profiles, and may form an important part of the structure of the jet impingement device. Tests by Lee and Lee [12] demonstrated that orifice nozzles produce higher heat transfer rates than a fully developed pipe flow at all radial positions, with local $N u$ increases of up to $65 \%$ at $H / D=2$ and up to $30 \%$ at $H / D=10$. This difference between the nozzle types becomes larger at decreasing $H / D$ values.

A slot jet, shown in Fig. 7, provides a heat or mass transfer pattern that varies primarily in one spatial dimension on the target wall, an advantage when uniformity of transfer coefficient is desired, but presents some structural disadvantages relative to a round nozzle array orifice plate. The use of multiple nozzles to cover a target surface offers some improvements in efficiency and uniformity of transfer properties with both twodimensional (slot) and three-dimensional nozzle geometries. For a typical single-round impinging jet the $N u$ values can vary by a factor of 4 or 5 from $r / D=0$ to 9 . The incorporation of a nozzle array can reduce this variation to a factor of 2. An array of pipe nozzles requires more effort to manufacture, but can also provide useful pathways for exiting flow.

\section{E. The Effect of Jet Pitch: The Jet-Jet Interaction}

The pitch $p_{j e t}$, or center-to-center positioning of jets in an array, determines the degree of jet interaction. For jets spaced at pitch-to-diameter

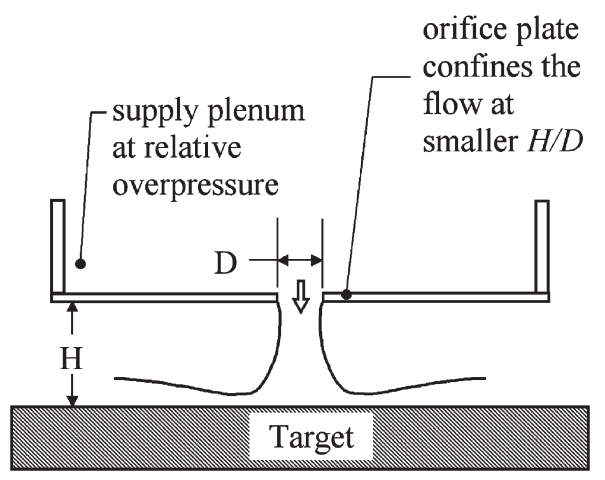

FIG.6. Orifice plate nozzle and supply plenum. 


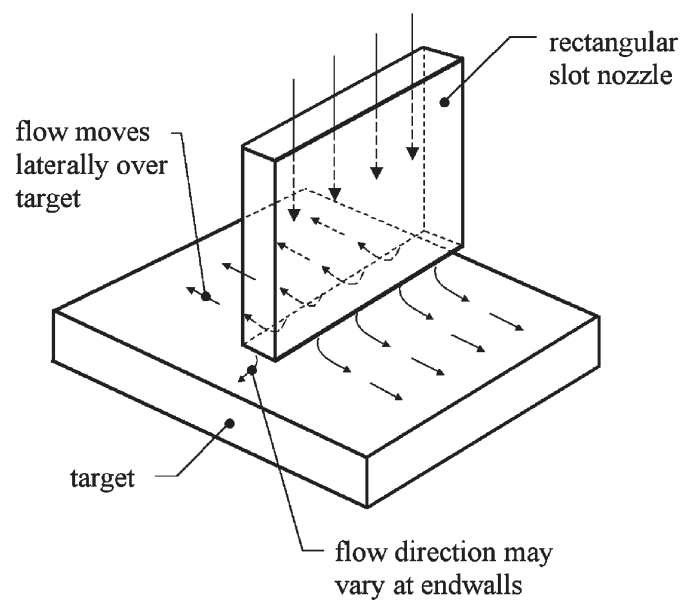

FIG. 7. Slot jet schematic.

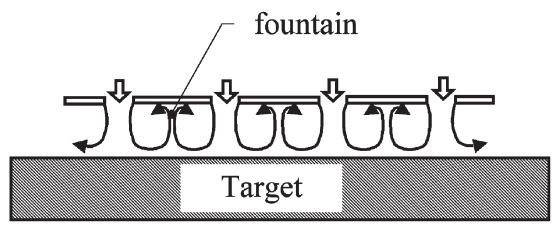

FIG. 8. Typical circulation pattern in the confined jet array.

ratio $p_{\text {jet }} / D<4$, the jets show significant interaction. San and Lai [27] showed that for $H / D=2$, the interference persisted up to spacings of $p_{\text {jet }} / D=8$ or 10 , and the maximal $N u$ occurred at $p_{\text {jet }} / D=8$.

\section{Shear Layer Interference}

At the small $p_{j e t} / D$ for moderate-to-large jet lengths (such as $p_{j e t} / D<2$, $H / D \geqslant 6)$, the growing shear-layer jet boundaries may influence each other. If the two neighboring shear layers grow and combine then the velocity gradient at the edge of the jet decreases in magnitude, reducing further turbulence generation and interfering with the generation of large-scale eddies. At the target impingement plate, the wall jets of two adjacent flows may collide, resulting in another local stagnation region or boundary layer separation, and a turning of the flow away from the wall into a "fountain" shape, shown in Fig. 8. This fountain effect can alter transfer rates in the location of colliding wall-jets, and for the highly constrained jets $(H / D<2)$ it may influence the free jet-shearing layer. If the fountain flow exchanges 
momentum with the free jet-shearing layer, the surface transfer rates are found to decrease [28]. In cases where the fountain is far from the free jet (large $p_{\text {jet }} / D$ ), the highly turbulent region beneath the fountain may have higher heat transfer rates than the upstream wall jet, with transfer rates of the same order of magnitude as those produced in the stagnation region.

\section{Small Jet Lengths and Highly Confined Jets}

Jet interaction in an array is also affected by the ratio of jet nozzle diameter to target wall spacing, $H / D$. At $H / D<0.25$, the fountain effect may not occur, but other undesirable flow patterns may develop. The mild fountain effects occurring for $H / D>1$ have a minimal effect on heat transfer, so the region in which fountain effects may degrade transfer is in the range $0.25 \leqslant H / D \leqslant 1[25]$. At low values of $H / D$ and low values of $p_{\text {jet }} / D$, the flow delivered by a single jet has limited space in which to exit the impingement region. As the flow travels along its exit pathway(s), the wall jets form a crossflow that encounters other jets. The presence of the crossflow causes asymmetric jet flow fields, moves stagnation points, disturbs other wall jets, and in general results in thicker boundary layers and reduced average transfer rates. The jet-to-jet interaction may not have a large influence on the peak $N u$ value, but the averaged $N u$ value shows a decrease due to the interference [29]. In experimental work with confined jet arrays, Huber and Viskanta [30] found that the major causes for the decrease in $N u$ due to jet-jet interaction take place before impingement, rather than in the wall jet or fountain region. With sufficiently small $H / D$, the flow pattern changes to give peak transfer coefficients off the central axis. For a round jet in a confined flow at $H / D=2$, Huber and Viskanta found the primary $N u$ peak in a ring-shaped region at $r / D=0.5$, as well as a secondary peak at $r / D=1.6$.

\section{Spacing and Interaction}

As a rule of thumb, the jet interaction plays a minor role for $p_{j e t} \mid D>8$ and $H / D>2$, and the undesired interference will increase as $p_{\text {jet }} / D$ and $H / D$ decrease from these values. Experiments have shown that the interference is much less sensitive to $R e$ than to these two geometric ratios [27]. Table II summarizes the expected interaction effects at various $H / D$ ranges.

\section{Crossflow and Target Motion}

The presence of a crossflow tends to disturb the impinging jet pattern, thicken wall boundary layers, and degrade transfer rates. Experimental work by Chambers et al. [31] modeled a turbine blade cooling channel 
TABLE II

Jet Height and Spacing Effects

\begin{tabular}{ll}
\hline H/D & \multicolumn{1}{c}{ Effect upon jet array } \\
\hline Up to 0.25 & $\begin{array}{c}\text { Highly constrained flow, may have strong crossflow and high additional } \\
\text { backpressure (on the order of magnitude of the nozzle exit dynamic } \\
\text { pressure). Additional flow acceleration expected to shift peak } N u \\
\text { laterally by } 0.5-1.5 D\end{array}$ \\
& $\begin{array}{l}\text { Fountain flow may greatly affect heat transfer in confined arrays } \\
\text { Mild fountain effects may occur. Minor turbulence generation. Flow } \\
\text { will be affected by confinement wall, need to ensure a clear exit } \\
\text { pathway }\end{array}$ \\
& $\begin{array}{l}\text { Shear layers may interact, need to maintain sufficient } p_{\text {jet }} \text {. Best } \\
\text { performance tends to lie in this range }\end{array}$ \\
Minimal confinement effect is overshadowed by nozzle type. Need to \\
ensure that neighboring jets remain separate \\
Confining wall does not influence flow, instead nozzle type and jet \\
spacing dominate the flow field. $N u$ affected by jet energy loss \\
approaching the wall. Need to ensure that neighboring jets remain \\
separate
\end{tabular}

including the crossflow due to spent flow passing thorough a confined channel. They found that as crossflow ratio (channel flow speed divided by jet speed) increased, the heat transfer patterns approached those of a film cooling design, with no impingement heat transfer enhancement at high crossflows. Centrifugal acceleration in rotating turbomachinery generates nonuniform supply pressures and generates secondary flows which add to crossflow effects in addition to creating radial variations in jet $R e$ and $N u$.

A series of experiments by L.W. Florschuetz et al. [32-34] mapped out the effects of jet nozzle spacing and the resulting crossflows in jet arrays. The results showed the immediate benefits of decreasing $D$ and allowing space between jets for the channeling of spent flow. They also measured downstream displacement of heat transfer maxima caused by crossflow.

In some applications, the jet impinges on a moving target, which makes the heat or mass transfer in the direction of motion more uniform. Continuous industrial processes such as drying of paper or rolling of sheet stock or external heat transfer to rotating parts require the solid material to move. Selection of an effective speed depends on the jet spacing or spatial extent of nonuniformities as well as a time constant associated with the rate at which heat or mass can be transferred to or from the target. For small 
lateral translation speeds compared to the jet speed, target wall speed $<0.2 U$, the motion has little effect on the fluid flow. When the wall velocity is higher, the effect is like that of superposing a crossflow. In a jet array this tends to decrease overall heat transfer, but with a single jet some overall benefit has been noted with target motion. Numerical investigation by Chattopadhyay et al. [35] found that for wall speeds greater than $U$, the turbulence production in the stagnation region is no longer dominated by wall-normal turbulent stresses but rather by wall-parallel velocity gradients and fluctuations in the wall-parallel fluid velocity component. Though industrial processes may use target speeds up to 10 times the jet speed, it was found that for a single jet a maximum averaged $N u$ occurred for target speeds at about 1.2 times the jet speed, with the maximum averaged $N u$ up to $25 \%$ higher than that with a stationary target [35].

\section{F. Alternate Geometries and Designs}

Creative designers have added features to the simple impingement designs described thus far, primarily to obtain higher heat transfer coefficients, at an acceptable pressure drop and energy consumption, constrained by strength, space, and cost considerations. Many nozzle types were tested, including cross- and star-shaped cross-sections, fluted, scarfed, tabbed, and angled nozzles. Some nozzles were structured to swirl the flow before allowing it to hit the wall, resulting in a higher flow speed at a given nozzle mass flow [36]. At $H / D>6$, the beneficial effects of swirl tend to be lost, but for $H / D \leqslant 2$ the swirl can make the $N u$ distribution more uniform, at the cost of a lower peak value [37]. At high swirl the stagnation region heat transfer may decrease due to the formation of a recirculatory region on the target immediately under the swirling jet [38]. Wen [39] coupled a swirling jet flow with an axial vibration of the target plate, thereby increasing the fluid turbulence, promoting separation, and impeding the development of a steady boundary layer. This produced increases in $N u$ of up to $20 \%$ using vibratory frequencies of up to $10 \mathrm{~Hz}$.

The jet impingement angle has an effect on heat transfer and was studied often. Impingement at an angle may be needed due to some unique feature of the hardware design, or is motivated by desire to reduce the penalties of jet interaction or to reduce losses in the approaching or spent-flow exit pathway. Inclination of the jet distorts the heat transfer contours, generating elliptical isoclines of $N u$. It was found that $N u$ decreases as the impingement incidence angle becomes smaller than $90^{\circ}$ (the normal direction) [40]. The maximum $N u\left(N u_{0}\right)$ occurs downstream of the intersection of the nozzle axis and the target. Experiments by Sparrow and Lovell [41] found a displacement of up to $2.25 \mathrm{D}$ for nozzle angles of $60^{\circ}$ off perpendicular, with a corresponding decrease in $S h_{0}$ or $N u_{0}$ of $15-20 \%$. Although the 
transfer rate pattern was affected by the jet inclination, the area-averaged transfer coefficient decreased by only $15-20 \%$.

Jet arrays with pulsed jets generate large-scale eddy patterns around the exit nozzle, resulting in unsteady boundary layers on the target that may produce higher or lower heat transfer coefficients, depending primarily on frequencies, dimensions, and jet Reynolds number. Bart et al. [42] demonstrated an increase of up to $20 \%$ in $N u$ for lower pulse frequencies $(200-400 \mathrm{~Hz})$ at moderate jet spacings $(H / D=4-6)$. The large scale, unsteady disturbance of the boundary layer can cause local minima and maxima in the heat or mass transfer profile, in general an improvement over a steady more insulative layer. This effect is balanced against the effect of disturbing or breaking up the large-scale eddies before they reach the wall.

Göppert et al. [43] investigated the effects of an unstable precessing jet over a fixed target plate. As with a pulsed jet, the variation in local fluid velocity over the target prevented the development of a steady boundary layer. This effect was counteracted by an increased tendency of the precessing jet to mix with the surrounding fluid, lose energy, and reach the target at lower velocities than would be found with a stationary jet $(H / D=25)$, resulting in a $50 \%$ decrease in wall-jet $N u$ values.

Nozzles structures may be more complex than the single flow channels described previously. Hwang et al. [44] altered the flow pattern in the initial shearing layer by using coaxial jets. The entry velocity in a second layer of jet flow surrounding the primary jet was varied to control vortex shedding rate and the persistence of large-scale vortices. Experimental results showed that with high flow speed in the secondary nozzle, the onset of vortex formation was delayed, which increased $N u_{0}$ by up to $25 \%$ for higher $H / D$ $(9<H / D<16)$. Some similar phenomena occur in the case of an annular jet, which produces $N u$ maxima spaced laterally outward from the center of the jet axis. It also creates a local $N u$ minimum on the target in the center of the annulus, where the flow washes upwards as a fountain and gets entrained into the surrounding annular jet [45]. The annular nozzle provides a means of widening the jet, and hence the stagnation region where $N u$ is highest, without increasing the required mass flow. This effect comes at a price, as the annular nozzle will have a higher wetted surface area and thus higher frictional losses and pressure drop. Compared to a cylindrical nozzle, the annular jet nozzle promotes additional turbulence downstream of the nozzle due to the internal and external shearing layers.

Alternate configurations may be dictated by the target surface or manufacturing process design, for example when cooling a rounded cylindrical object. Jet impingement on a cylindrical target generates a heat transfer pattern similar to that of a cylinder in crossflow. As expected, the greatest transfer coefficients occur in the stagnation region, and the lowest occur far along the 
cylinder surface downstream from the impingement point. In turbulent jet flows the minimum transfer rate occurs at cylinder azimuthal angles about 90 degrees from the impingement point with the transfer rate rising again when the boundary layer becomes turbulent further along the cylinder circumference, and often yet again in the turbulent wake on the back half of the cylinder. In slower, transitional flows $N u$ decreases continually along the cylinder surface, resulting in a minimum $N u$ directly opposite to the impinging point, in the center of the flow wake. Gau and Chung [46] found that for slot jets on convex targets, $N u_{0}$ was proportional to $\left(d_{\text {target }} / B\right)^{-0.14}$ for $2 \leqslant H / B \leqslant 8$ and $N u_{0}$ was proportional to $\left(d_{\text {target }} / B\right)^{-0.15}$ for $8 \leqslant H / B \leqslant 16$. For concave targets they determined $N u_{0}$ was proportional to $\left(d_{\text {target }} / B\right)^{-0.38}$ for $2 \leqslant H / B \leqslant 16$. At higher curvatures the cylinder in crossflow experiences flow separation on the surface and earlier breakdown of surface eddies, though the wall jet tends to follow the curvature of the wall (stabilizing Coanda effect). Fleischer et al. [47] studied the effects of a jet on a cylinder and found separation angle to depend on not on $R e$ but on cylinder curvature relative to jet diameter. The flow separation from the target surface results in a rapid decrease in heat transfer rates. Slot jet experiments by Gori and Bossi [48] using a cylindrical target found that the maximum average $N u$ occurred at $H / B=8$. Convex target curvature reduces turbulence adjacent to the wall as the turbulence of the upper shear layer of the wall jet must spread farther laterally. Purely convective transport will carry the shear layer around the curved target but will not contribute to the increase in turbulence in the lower portion of the wall jet.

Cooling by impinging jet yields higher heat transfer rates than immersing a cylindrical target in a uniform flow field having the same flow speed (same $R e$ ). McDaniel and Webb [49] found that the average transfer rate on the surface was up to $40 \%$ higher than that of the parallel flow case for a rounded nozzle, and up to $100 \%$ higher with a sharp orifice nozzle. Compared to a uniform freestream flow, the impinging jet nozzle accelerates the flow on approach to the target cylinder, and adds turbulence in the approach to the stagnation region.

Concave target surfaces, such as those found in the front of an impingement-cooled turbine blade, present different flow fields. In general, the resulting pressure gradients tend to reduce the boundary layer growth and improve heat transfer. As summarized by Han et al. [7], the shape of the Nusselt number profile in the concave leading edge of a turbine blade has only weak dependence on $H$ or $R e . N u / N u_{0}$ drops to only 0.4 at a lateral position of $x / D=4$, with a flatter profile shape (smaller $d N u / d x$ ) than that seen on convex or flat target surfaces. Surface-curvature-forced recirculation of the jet flow in and around the stagnation region tends to disperse largescale turbulent structures more rapidly, leading to a more unsteady turbulent wall flow without large coherent structures [50]. 
Experimental work with a slot jet showed the peak $N u$ moved outwards to 0.4-0.6 jet widths off of the central axis, with a local depression in $N u$ at the stagnation point of $7-10 \%$ below maximum $N u$ [51]. A series of experiments by Taslim et al. [52] studied the effects on $N u$ of geometric changes to a concave target representing the leading edge of a turbine blade. They found that the inclusion of conical bumps on the target surface did not improve the heat transfer per unit area, but increased the target heat transfer area while maintaining the same $N u$, which generated an overall increase in heat transfer rate of up to $40 \%$.

Impinging jets are used with other target modifications such as ribbed walls. The inclusion of ribs on the target surface disturbs the wall jet and increases turbulence. The ribs may also function as fins to increase the effective surface area for transfer of energy. While the ribs increase the transfer rates outside the stagnation region, the heightened drag of the ribs causes the wall jet to decelerate and disperse more rapidly, decreasing $\mathrm{Nu}$ far from the stagnation region. Experiments by Gau and Lee [53] found that in regions of low jet turbulence the space between the ribs can fill with an "air bubble" (a local region of low speed flow), which reduced $N u$ by $20-50 \%$. By reducing rib height to $15 \%$ of the nozzle width and raising the nozzle to $H / D>6$ they were able to set up a recirculating flow in these spaces and improve local $N u$ in the stagnation region. The resulting value of $N u_{0}$ at $H / D=10$ increased by up to $30 \%$ compared to a flat target.

A series of additional holes in the fluid supply plate of an orifice array, designed for the spent flow, can provide benefits in cases with restrictive exit pathways. These effusion holes vent to exit ducting or the surroundings to provide a lower-restriction exit pathway for spent air. The addition of effusion holes increases average transfer rates for $H / D<2$ [54]. Rhee et al. [54] showed a 50\% improvement in jet array average transfer rate at $H / D=0.5$ by adding effusion holes, but noted minimal influence for $2<H / D<10$. The integration of a low-loss exit pathway into an impingement cooling device poses a design problem for which some simple solutions exist, but many more efficient approaches are possible. In a turbine blade the preferred effusion pathways are either through holes in the target wall itself (the blade exterior) to form a film cooling layer on the opposing surface, or through the confined flow region leading to aerodynamically favorable exit holes on or near the trailing edge of the blade.

Impinging jets are not limited to single-phase flows. Impinging gas jets containing liquid droplets, for example in the case of engine fuel injection, deliver a large increase in heat transfer resulting from the inclusion of the droplets. Numerical modeling by Li et al. [55] showed conduction from the wall to the droplets served as the major heat transfer path in the apparatus, with heat transfer rates raised by up to $50 \%$ at a liquid-gas mass ratio of 
$10 \%$. In the extreme case, a high enough liquid content in a gaseous environment will result in a free surface jet, rather than a submerged jet, and only a small influence due to shearing forces between the gas and the liquid surfaces. The inclusion of small solid particles in an impinging jet flow will improve heat transfer as the particles impact the target [56]. In the stagnation region, the rebounding particles will increase the turbulence level. This technique has been shown to raise $N u_{0}$ by up to 2.7 times that seen with a single-phase flow. In the wall jet, the particles will disturb the boundary layer and can thus increase heat transfer. High volume fractions of large particles can have a detrimental effect as they disrupt the formation and transport of large-scale eddies in the flow field [57].

The case of flame impingement forms a special subclass of jet impingement [5]. A jet carrying a reacting fuel transfers heat very effectively and tends to have higher turbulence. If some fuel travels through the stagnation region without complete combustion, further reaction in the wall jet will release additional thermal energy and improve the uniformity of the heat transfer. In addition to the convective mechanism, a flame impingement device also transfers heat to the surface by radiation from the flame. Experiments by Malikov et al. [58] demonstrated a flame impingement device in which convective heat transfer accounted for $60-70 \%$ of the heat transfer, with the remaining heat transfer primarily by radiation. For typical hydrocarbon fuels such as methane the concentration of fuel and of any supplemental oxygen in the flow (fuel-air equivalence ratio) must be controlled to limit accumulation of soot on the target surface, which will ultimately impede heat transfer. Interaction of neighboring jets may also alter the fuel concentration pattern and ultimately degrade heat transfer, including in wall jet fountain flows [59]. A number of analytical tools for predicting flame impingement heat transfer were published by Baukal and Gebhart $[60,61]$.

\section{Research Methods}

Current research in improving impingement jet performance and predicting jet behavior falls into two categories, experimental and numerical. Where possible, researchers use experimental results to assist in the development and validation of numerical tools for predicting flow and heat transfer behavior.

\section{A. Experimental Techniques}

Impingement heat transfer experiments focus on measuring the flow field characteristics and the surface heat transfer coefficients. In an experiment a single jet or jet array is constructed and positioned above a solid target such as a plate or cylindrical surface. A pump or blower forces fluid onto the 
target plate while instrumentation collects information about fluid properties and target surface properties.

The target surface used is often supplied by a controlled constant heat flux $\left(q^{\prime \prime}\right)$ using electrically resistive embedded heating strips or a resistive film in the target plate. To reduce lateral heat transfer within the target plate, which would make measurements more complicated, low thermal conductivity and/or thin target materials are chosen. The back side of the target is insulated to minimize energy loss to the surroundings and resultant uncertainty in the heat flux into the fluid. The end result is that the energy generated travels into the fluid in a one-dimensional pathway normal to the surface, with a uniform heat flux.

The surface heat transfer coefficient is evaluated using the equation

$$
h=\frac{q^{\prime \prime}}{\left(T_{s}-T_{f}\right)}
$$

where $T_{s}$ and $T_{f}$ are the measured surface and far-field fluid temperatures, respectively. The temperature measurement is performed either by conventional temperature sensors at discrete locations, or for the entire surface at once by non-contact optical devices such as infrared (IR) radiometers, thermally sensitive paints, and frequently by thermochromic liquid crystals (TLC) [62-64] that change their color with temperature.

When using thermocouples and other direct temperature sensors, they must be embedded in or carefully bonded to the target surface to give a proper reading. Rather than install a large array of thermocouples, some experiments use a single sensor mounted on the target, and move the target, thus positioning the sensor at different lateral positions relative to the jet axis. Such an approach is good only for large targets with small variation in their surface heat flux and small lateral thermal conductance.

TLC or other "temperature paints" change color with temperature. As part of the experiment, reference measurements are made to calibrate the paint response and build calibration curves of surface temperature vs. paint color [65].

This method allows the researcher to rapidly capture a complete high spatial resolution temperature distribution using photography, and process the images during or after the experiment. A drawback of the method is that most TLC materials undergo a full color transition over a narrow range of temperatures (e.g. $2-4{ }^{\circ} \mathrm{C}$ ), which is often smaller than the full range of temperature on the target. As a solution, many researchers sequentially vary the heat flux in the experiment, causing the indicator color transition to occur at different locations on the target, and then collecting the results in one spatial plot of $N u$. The accuracy of this method depends on the 
assumption that $N u$ does not vary significantly with heat flux. This method effectively turns an experiment at constant heat flux into an experiment with small, almost constant wall temperature, with the intent of producing equally valid results. Alternately, the experiment may use multiple closely spaced temperature paints with different transition ranges, sacrificing some spatial resolution [66]. Ultimately, the TLC must be selected based on ease of application and use, color transition sensitivity, and transition temperature range, balancing this against the difficulty in carefully maintaining fluid supply temperature and the error associated with making measurements at a small local heat flux or various heat fluxes (a potential consequence of using a TLC with a narrow temperature range).

Temperature patterns on the surface may be determined by measuring the intensity and spectral characteristics of the radiation emitted from the target. Many experimenters have successfully collected temperature data using long-wave IR cameras. For such an application, the surface is coated with a paint of known emissivity, and the instrumentation setup is calibrated using thermocouples, optical targets, or other sensors to define a calibration curve of temperature vs. radiation intensity. Commercial IR cameras come with software to collect, store, and process images as well as provide temperature scales given information about target emissivity. With the continuing improvements in digital photography, both this approach and the temperature paint/TLC methods are well-suited to digital postprocessing to preserve a high level of spatial resolution in the data.

For mass transfer experiments the target surface is usually maintained at a set mass concentration, and the experiment tracks the amount of material removed over time. The target surface has a coating of a chemical film such as naphthalene. After running the apparatus for a set period of time, measurements are made to determine the change in the thickness of the chemical film, and therefore the rate of mass transfer. This yields a twodimensional map of the Sherwood number on the target surface. Other coarser approaches have used a porous target material containing a known level of chemical, such as cloth strips soaked in water, and weighed the target material to determine the mass change over time.

A great number of techniques for measuring the flow field have been applied, including visualization by using smoke, paint, or other tracers, by Pitot and static probes, and hot-wire anemometers for discrete location measurements, and by the essentially noninvasive particle image velocimetry (PIV), particle tracking velocimetry (PTV), and laser doppler anemometry (LDA) for the entire viewed flow field.

For simple flow field visualization, the use of smoke, paint, and tracer particles provide clear visual pictures of initial streaklines, large-scale eddies, regions of flow separation and reversal, and onset of turbulence. Coarser 
time-averaged data providing fluid static and dynamic pressure can be tracked using Pitot and static probes, but these are used less due to the availability of smaller and more precise and sensitive devices.

For detailed, local measurements of fluid velocity, the hot-wire anemometer (HWA) remains the sensor of choice. The wire may be traversed through the flow field to construct a three-dimensional field of data. By utilizing one or more wires at different orientations, one can measure multiple velocity components. With a thin wire and a circuit delivering rapid time response, the anemometer can capture the rapid velocity variations associated with a turbulent flow. Instrumentation programs take the "jittery" time histories recorded by the HWA and process the signal, producing turbulent velocity (r.m.s.), turbulence intensity, and even frequency-amplitude plots of turbulent flow.

PIV and PTV techniques use small tracer particles to determine fluid velocity. By illuminating a thin layer of fluid using a sheet of laser light, the particles in a planar slice of the flow can be photographed at small time intervals. The change in position of a discrete particle between successive frames gives an indication of its velocity within the two-dimensional reference frame of the photograph. The velocity field through the whole flow field is measured by moving the light sheet to different positions within the flow. A velocity field with three components may be established by taking "slices" in multiple directions, but this requires a more complex experimental apparatus and is not performed as frequently as 2-D PIV. Experiments also use other tracer-based techniques such as Laser Doppler Anemometry.

The experimental results are typically correlated by the form

$$
N u=C \operatorname{Re}^{n} \operatorname{Pr}^{m} f(H / D)
$$

where $f(H / D)$ is an empirically determined function and $C, n$, and $m$ are constants determined by experiment. Additional dimensionless parameters may be added to the correlation to account for other important effects, such as jet pitch, angle of incidence, surface curvature, pressure loss, etc.

\section{B. Modeling}

The designer of an impinging jet device needs to predict the transfer coefficient profile $(\mathrm{Nu})$, necessary fluid flow $(G)$, and pressure drops in advance of manufacturing the hardware. Highly accurate models or calculation methods are desirable as they minimize the amount of testing required. A reliable set of models provides the designer with a rapid, inexpensive, and flexible alternative to conducting a series of hardware tests. 


\section{Empirical Correlations}

First, simple correlations such as those supplied by Martin [2] (with a summary in [1]) predict $N u$ as a function of the governing parameters in cases where the fluid has a continuously laminar flow $\left(R e_{j e t}<1,000\right.$, $\left.R e_{\text {wall }}<10,000\right)$ over the entire fluid and target region of interest. A survey of available impingement heat transfer correlations is collected in the appendix of this review.

\section{Laminar Impingement}

For laminar flows in many geometries, the governing equations may be reduced to analytical solutions, such as that for a stagnating flow field placed above a wall boundary layer [67]. Numerical modeling of steady laminar flows is fairly straightforward, using the mass, momentum and energy conservation equations in time-invariant forms. This simulation approach may even yield useful results for flows which are laminar over most but not all of the domain. Kang and Greif [68] successfully predicted flow field properties, separation locations, and heat transfer coefficients for impinging jets on cylinders for $100 \leqslant R e \leqslant 1000$, including exploration of buoyancy effects.

\section{Turbulent Impingement Models}

Most impinging jet industrial applications involve turbulent flow in the whole domain downstream of the nozzle, and modeling turbulent flow presents the greatest challenge in the effort to rapidly and accurately predict the behavior of turbulent jets. Numerical modeling of impinging jet flows and heat transfer is employed widely for prediction, sensitivity analysis, and device design. Finite element, finite difference, and finite volume computational fluid dynamics (CFD) models of impinging jets have succeeded in making rough predictions of heat transfer coefficients and velocity fields. The difficulties in accurately predicting velocities and transfer coefficients stem primarily from modeling of turbulence and the interaction of the turbulent flow field with the wall.

The computation grid must resolve both the upstream and downstream flow around the nozzles or orifices and must extend sufficiently far to the side of a single jet or array (typically eight to ten diameters) to provide realistic exit conditions. Zero-gradient and constant-static-pressure conditions have been used at the far-field model boundaries. Successful, stable modeling using both of these conditions can depend on properly shaping the boundary at the edge of the model domain. Turbulent impinging jet CFD 
employs practically all available numerical methods that will be critically reviewed in the following sections.

An earlier critical review of this topic was conducted by Polat et al. in 1989 [69]. Since that date, the variety of numerical models has grown and computational research has taken on a larger importance in predicting the physical behavior of impinging jets. The continuing increase in computing power has enabled more rapid computation including optimization by parametric variation. An inexpensive desktop computer may solve precise, high-resolution two-dimensional models within a day. Three-dimensional models and unsteady models are now possible without the use of supercomputers, and have execution times ranging from several days to several weeks. The examples in the following review are primarily from impinging jet numerical modeling conducted since the original review by Polat $e t$ al.

Useful as a theoretically simple approach, the direct numerical simulation (DNS) method is the most complete and physically exact numerical method employed to predict the impinging jet flow field and transfer rates. This method solves the full Navier-Stokes, continuity, and energy/mass diffusion equations using discrete units of time and space, but requires an extremely small grid to fully resolve all the turbulent flow properties, because the microscopic turbulent length scales involved in jet impingement are far smaller than the macroscopic lengths involved (e.g. $D_{0}$ or $H$ ). The consequently long computation time practically limits the use of DNS to Reynolds numbers much lower than those in the gas turbine impingement heat transfer application. Since the DNS computational time to resolve turbulent eddies grows with the local turbulent Reynolds number $\left(R_{t}\right)$ to the third power, this modeling method may be of academic interest for laminar flows but will remain impractical for turbulent jets for the foreseen future. Typical DNS CFD studies, using supercomputers, were limited to Reynolds numbers of the order of 10,000. To represent practical application successfully, the majority of DNS computations were limited to $\operatorname{Re}<1,000$, with even lower limits for highly complex flows.

In an attempt to remedy this situation, some CFD models use Large Eddy Simulation (LES). The time-variant LES approach tracks flow properties with the full equations down to some user-defined length scale (typically the grid spacing), and then uses additional sub-grid-scale equations to describe turbulent flow behavior at smaller scales. The LES method has shown encouraging results and clarified the understanding of formation, propagation, and effects of flow eddies upon the velocity fields and jet transfer characteristics [19,70-72], but it requires high resolution in space for accuracy, may require high resolution in time for stability and accuracy, and therefore still needs a great amount of computing power or time to produce satisfactory solutions for the transitional and turbulent flows of interest here 
(Re $>1000)$. Modeling by Cziesla et al. [73] demonstrated the ability of LES to predict local $N u$ under a slot jet within $10 \%$ of experimental measurements. The use of LES does not necessarily have an upper or lower limit on $R e$ (though particular codes may be limited to $M \leqslant 1$ ), but for laminar flows $(\operatorname{Re}<1000)$ the influence of turbulence is small enough that the DNS approach offers little improvement in accuracy over the timeaveraged techniques detailed in the following sections. For those cases where computational cost is not a primary concern, the LES method offers the greatest information about the impinging jet flow field.

Steady-state time-averaged solution techniques, typically Reynoldsaveraged Navier-Stokes (RANS) models, use some version of the Navier-Stokes equations adjusted for the presence of turbulent flow. The majority of RANS models used for jet flows fit into one of two categories, the two-equation eddy-viscosity models and the computationally more costly full second moment closure (SMC) models. Eddy viscosity models treat the turbulent viscosity as a scalar quantity, assuming or forcing an isotropy in the normal stresses [74]. The various full SMC models track all Reynolds stresses or track the various components of an anisotropic turbulent viscosity. These models approximate the Reynolds stresses and heat fluxes using semi-empirical equations based on expected physical trends rather than direct derivations. The semi-empirical equations provide approximations of undetermined terms within the second-moment equations, typically two-parameter correlations. With further manipulation, a series of higher-order-moment equations can be generated, but these more complex models have even more correlation terms and unknowns which require approximate modeling.

\section{Near-Wall Treatment}

In addition to the portions of the CFD model describing the fluid flow inside the computational domain, the steady and transient models require a description of how the flow behaves next to the wall (the target surface). This part of the model typically plays the major role in properly predicting both the flow and the heat transfer [75]. The fundamental difficulty comes from the need to describe how the turbulent regions of a decelerating flow field interact with the wall, including in the wall boundary layer. A variety of often very different wall reflection terms have been implemented. Numerical solutions have shown that heat transfer rates within the viscous sublayer are of a larger magnitude than outside the layer. The spatial region in which the turbulence models have the greatest difficulty approximating the flow is the same region in which the largest heat and mass gradients occur, and so this region cannot be neglected. 
Numerical models of turbulence near the wall commonly feature one of two approaches. In the first approach, the grid near the wall is constructed at sufficiently high resolution to properly resolve flow in the entire viscous sublayer and turbulent boundary layer with turbulence equations intended for use at low cell Reynolds numbers. This requires a model capable of resolving turbulent behaviors very close to the wall, and a large computation effort.

The alternate method uses algebraic equations to relate steady and fluctuating velocity and scalar profiles to wall distance and surrounding fluid properties. These wall functions predict the flow properties in and above the viscous sublayer. This method requires only a single cell in the sublayer, and thus requires less computational time. Relations for high $R e$ parallel flows such as the "Law of the Wall" are based upon flows in different geometry than that of the impinging jet, and may not produce a correct velocity profile near the wall, especially in cases where the flow separates or reverses on the target surface. The standard Law of the Wall is based upon the absence of pressure gradients near or along the wall, clearly a different flow field than that seen in the stagnation region of an impinging jet. The Nonequilibrium Law of the Wall is based upon differing turbulent energy generation and destruction rates and accounts for pressure gradients. Bouainouche et al. [76] performed modeling with various wall equations and concluded that the standard logarithmic Law of the Wall poorly predicted shear stresses (errors of up to $-30 \%$ in the stagnation region) and that a generalized Non-equilibrium Law of the Wall performed well in the stagnation region but underpredicted wall shear stress in the wall-jet region (errors of up to $-12 \%$ ). Their "Hybrid Law of the Wall" model produced improved results by using the non-equilibrium Law in the stagnation region and switching to the logarithmic law in the wall-jet region.

Esch et al. [77] used a scalable wall function to resolve this problem, enforcing a limit on the length used for calculating the wall shear stress to force the first grid node off of the wall to lie outside the sublayer. At higher resolutions, this method effectively defines the wall surface of the CFD model as the outside of the viscous sublayer. This flexible wall function approach is recommended for the impinging jet application as it reduces computational effort without changing the governing equations.

Specific difficulties arise with the numerical modeling of impinging jets. A number of models reviewed in the following sections, such as $k-\varepsilon$, have been optimized for free-shear flows such as submerged jets. Some models, such as $k-\omega$, perform best in boundary-layer flows such as the wall-jet region. Unfortunately, the impinging jet problem contains both of these as well as significant pressure gradients in the stagnation region. The normal strain, and rise in fluid pressure in the stagnation region, affect the turbulent flow 
through distinct terms in the second-moment RANS equations. The pressure plays a part in the turbulent diffusion term. The effects of changing pressure play an even greater role in the pressure-strain rate correlation term. Unlike the turbulent diffusion term, which most models focus on approximating, the pressure-strain correlation was usually of secondary interest. As a result, most models produce less accurate predictions for turbulent effects in the stagnation region. The pressure-strain rate correlation is typically divided into two parts, a "slow" pressure strain term tied to the turbulence dissipation rate or gradients of the velocity fluctuations, and a "rapid" term based on the gradient of the time-averaged velocity [18]. A wide variety of equation sets have been implemented to model these terms, with varying success. The two equation eddy-viscosity models, such as $k-\varepsilon$, contract the rank-2 tensors in the equations to eliminate terms, and thus drop these terms. That is, the two-equation models are based around assumptions about the low importance of pressure gradients and the minimal anisotropy of the Reynolds stresses, and experiments have shown that these modeling assumptions do not apply in the stagnation region.

\section{The Boussinesq Approximation}

The simplified RANS models need some approximation to determine the Reynolds stresses. An equation known as the Boussinesq approximation (or hypothesis) describes a simple relationship between turbulent stresses and mean strain rate. Given a strain rate tensor $S_{i j}$, where

$$
S_{i j}=\frac{1}{2}\left(\frac{\partial \bar{u}_{i}}{\partial x_{j}}+\frac{\partial \bar{u}_{j}}{\partial x_{i}}\right)
$$

the approximation gives a formula for the Reynolds stress tensor:

$$
-\rho \overline{u_{i}^{\prime} u_{j}^{\prime}}=2 \mu^{\prime}\left(S_{i j}-\frac{1}{3} S_{k k} \delta_{i j}\right)-\frac{2}{3} \rho k \delta_{i j}
$$

By itself, the Boussinesq approximation does not constitute a complete turbulence model, as the value of $\mu^{\prime}$ is unknown and depends on turbulence scales unique to each problem.

\section{The $k-\varepsilon$ Model}

The commonly tested " $k-\varepsilon$ " eddy viscosity model is widely acknowledged as producing poor results in the impinging jet problem, but remains a benchmark against which to compare better models. The $k-\varepsilon$ model remains 
in use due to its common implementation and comparatively low computational cost. The model uses the Boussinesq hypothesis to calculate the Reynolds stresses as a direct function of the velocity gradients and is based on flow behavior at higher Reynolds numbers (fully turbulent fluid flow). It independently tracks turbulent energy $k$ and turbulence destruction or dissipation rate $\varepsilon$, with a dissipation equation based upon expected trends. As with other RANS models it requires experimentally determined constants to fully close the equations. The $k-\varepsilon$ model can produce acceptable results for free-shear flows but provides poor simulation of wall-jet flows. The model requires the user to specify $\varepsilon$ at each boundary, but at the walls $\varepsilon$ has a finite, non-zero value, which is not known in advance. For the impinging jet problem it gives useful results in the free-jet region, but poor results in the stagnation region and wall jet region, as detailed in the following discussion of experimental work. It gives poor predictions of the location of separation points on solid boundaries and for the impinging jet problem it may fail to predict the occurrence of secondary peaks in $N u$. The standard $k-\varepsilon$ model is formulated for flows at high Reynolds number. It does not apply in regions where viscous effects on the flow field are comparable in magnitude to turbulent effects (such as in the sublayer next to a wall). In many cases, the model uses wall functions to determine the velocity profiles. Alternately, $k-\varepsilon$ models have been built with additional terms and damping functions to allow the model to simulate portions of the flow at low Reynolds numbers.

The following equations form the Launder and Sharma low Reynolds number model used by Craft et al. [75] in a comparative CFD study with only minor notation changes. It incorporates conservation equations for $k$ and $\varepsilon$ as well as a simple equation to set the velocity-temperature correlation (heat flux) proportional to the temperature gradient:

$$
\begin{gathered}
\frac{D k}{D t}=\frac{\partial}{\partial x_{j}}\left[\left(v+\frac{v^{\prime}}{\sigma_{k}}\right) \frac{\partial k}{\partial x_{j}}\right]+v^{\prime}\left(\frac{\partial \bar{u}_{i}}{\partial x_{j}}+\frac{\partial \bar{u}_{j}}{\partial x_{i}}\right) \frac{\partial \bar{u}_{i}}{\partial x_{j}}-\varepsilon \\
\frac{D \tilde{\varepsilon}}{D t}=c_{\varepsilon 1} \frac{\tilde{\varepsilon} v^{\prime}}{k}\left(\frac{\partial \bar{u}_{i}}{\partial x_{j}}+\frac{\partial \bar{u}_{j}}{\partial x_{i}}\right) \frac{\partial \bar{u}_{i}}{\partial x_{j}}-c_{\varepsilon 2} f_{\varepsilon} \frac{\tilde{\varepsilon}^{2}}{k}+2 v v^{\prime}\left(\frac{\partial^{2} \bar{u}_{i}}{\partial x_{j} \partial x_{k}}\right)^{2} \\
+\frac{\partial}{\partial x_{j}}\left[\left(v+\frac{v^{\prime}}{\sigma_{\varepsilon}}\right) \frac{\partial \tilde{\varepsilon}}{\partial x_{j}}\right]+Y_{c} \\
\overline{u_{i} T}=-\frac{v^{\prime}}{\sigma_{\theta}} \frac{\partial \bar{T}}{\partial x_{i}}
\end{gathered}
$$




$$
\begin{gathered}
Y_{c}=c_{w}\left(\frac{k^{3 / 2}}{c_{1} \tilde{\varepsilon} y}-1\right)\left(\frac{k^{3 / 2}}{c_{1} \tilde{\varepsilon} y}\right) \frac{\tilde{\varepsilon}^{2}}{k}=\text { Yap correction } \\
\varepsilon=\tilde{\varepsilon}+2 v\left(\frac{\partial\left[k^{1 / 2}\right]}{\partial x_{j}}\right)^{2}=\text { turbulent kinetic energy dissipation rate } \\
v^{\prime}=\frac{c_{\mu} f_{\mu} k^{2}}{\tilde{\varepsilon}}=\text { turbulentviscosity } \\
f_{\mu}=\exp \left(\frac{-3.4}{\left[1+\left(R_{t} / 50\right)\right]^{2}}\right)=\text { damping function } \\
R_{t}=\frac{k^{2}}{v \tilde{\varepsilon}}=\text { turbulent Reynolds number }
\end{gathered}
$$

where $c_{n}$ and $\sigma_{n}$ values are empirical constants, given as $c_{\varepsilon 1}=1.44$, $c_{\varepsilon 2}=1.92, c_{\mu}=0.09, c_{w}=0.83, c_{1}=2.5, \sigma_{k}=1.0, \sigma_{\varepsilon}=1.3$, and $\sigma_{\theta}=0.9$.

This example model includes the Yap correction term to adjust the dissipation rate $\tilde{\varepsilon}$ as a function of $k, \tilde{\varepsilon}$, and distance from the wall $y$. At low $R e$ the damping function $f_{\mu}$ adds an adjustment to the turbulent viscosity used in the conservation equations. It increases the dissipation to reduce the turbulent length scale. Without the correction, the model will overpredict turbulent length scale and overpredict turbulent viscosity. From the equations and set of constants one can see that the model depends highly on empirical data, and that the correction terms and associated constants are therefore somewhat arbitrary. The adjustment and constants provided incorporate the best knowledge available at the time, but engineers continually invent alternate adjustment terms with different closure coefficients.

Heyerichs and Pollard [78] conducted a numerical comparison of three different wall function and five different wall damping functions with an impinging jet test case and concluded that the selected $k-\varepsilon$ models with wall functions gave consistently poor results, with $N u$ errors in the range of 
-21.5 to $-27.8 \%$ in the stagnation region, and +32 to $+38.4 \%$ at the secondary peak. Somewhat better matches were produced using models with damping functions, but those models still produced errors in $N u$ of up to $50 \%$ and misplaced the secondary peak. They concluded that basing the damping functions on wall position $\mathrm{y}^{+}$caused the poor results, as the damping functions using $\mathrm{y}^{+}$were based upon simple wall-parallel flows with simple boundary layers, rather than the flow found in the stagnation region of the impinging jet.

Craft et al. [75] presented a comparison of a 2-D implementation of the $k-\varepsilon$ model vs. test data. For the test case at $R e=23,000$ the model predicted centerline wall-normal r.m.s. velocity levels up to four times larger than those measured in the experimental work of Cooper et al. [22]. A specific problem noted in the $k-\varepsilon$ model was that the model equation relating turbulent kinetic energy to turbulent viscosity caused increasing and erroneous turbulent kinetic energy levels in the stagnation region (increasing turbulent viscosity caused increasing turbulence intensity). The model similarly overpredicted wall normal r.m.s. velocity at $r / D=0.5$, corresponding to the edge of the jet. Wall-parallel velocity errors were in the range of $15-20 \%$, with errors of up to $50 \%$ in the $y / D<0.05$ region very close to the wall. The model overpredicted $N u$ in the center of the impingement region by up to $40 \%$ and failed to predict the secondary $N u$ peak at $r / D=2$. Craft et al. [79] continued work with this type of model, developing an alternate $k-\varepsilon$ model which produced greatly improved impingement centerline wallnormal fluctuating velocity values and better $N u$ predictions in the $r / D<2$ region. The largest errors in $N u$ were typically $15 \%$, occurring in the range of $1<r / D<3$. Turgeon and Pelletier [80] built adaptive $k-\varepsilon$ models which succeeded in generating a solution with minimal grid dependence, showing that the difficulties with applying the $k-\varepsilon$ model are independent of grid resolution and persist for small mesh sizes. Merci et al. [81] devised and tested an altered non-linear variation of the $k-\varepsilon$ model, yielding improved results over the standard model but an underprediction of $N u / N u_{0}$ of up to $25 \%$ (alternately interpreted as an overprediction of $N u_{0}$ ). Souris et al. [82] showed that the upstream errors in low Reynolds number $k-\varepsilon$ model predictions resulted in large downstream errors, giving wall jet thicknesses up to double that of experiment, and wall jet peak velocity as much as $44 \%$ below experimental results.

Tzeng et al. [83] compared seven low-Re modifications of the $k-\varepsilon$ model using a confined turbulent slot jet array problem with three adjacent jets at $H / B=1$. Each model used different adjustments to the $\varepsilon$ equation to account for damping effects near the target wall, based on functions of $k^{2} /(v \varepsilon), y\left(k^{0.5}\right) / v$, and/or $(v \varepsilon)^{0.25} y / v$. The models were each run with three separate finite differencing formulas, specifically the power law, 
second-order upwind, and QUICK schemes. Out of this large array of combinations, no single set of results consistently improved the $\mathrm{Nu}$ prediction when compared to the standard $k-\varepsilon$ model. Instead, various models produced local improvements at the cost of increased error at other positions. In the region around the central jet $(x / B<7)$ the standard $k-\varepsilon$ model produced better results than any of the low- $R e$ models, matching $\mathrm{Nu}$ within $7 \%$. In the regions where exhausting fluid placed impinging jets in a crossflow, the results varied a great deal. The standard $k-\varepsilon$ model (QUICK) errors ranged as high as $20 \%$ under the impinging slot jet in crossflow. The worst models had $N u$ prediction errors as great as $-65 \%$. The favored model was the low-Re model of Abe, Kondoh, and Nagano [84] plus the QUICK scheme [85], which matched the $N u$ profile within $15 \%$ for crossflow regions of the target, with an error of up to $-25 \%$ in the central wall-jet region prior to the crossflow.

From the various studies conducted, we can conclude that the even the best $k-\varepsilon$ models and associated wall treatments will yield $N u$ profiles with local errors in the range of $15-30 \%$, and the standard $k-\varepsilon$ model is not recommended for use in the impinging jet problem. These shortcomings are attributed to the assumption of isotropic turbulence and the use of wall functions that poorly approximate near-wall velocity fluctuation and associated transport properties.

\section{The $k-\varepsilon R N G$ Model}

Other variations of the model have been applied, such as the Renormalization Group Theory $k-\varepsilon$ model (RNG). The RNG model incorporates an additional term in the turbulent energy dissipation equation based on strain rates, and includes adjustments for viscous effects at lower $R e$ and a calculation of turbulent Prandtl number. Heck et al. [86] showed the RNG model provided a close match of $N u$ in the wall-jet region but an error up to $10 \%$ in the stagnation region. This is in part due to the RNG model's tendency to predict jet-spreading rates that are as high as twice that found in experiment [87]. This flaw on the upstream end of the model leads one to question how the downstream results did not stray as far from measured values. It offers some improved performance over the standard $k-\varepsilon$ at a slightly higher computational cost and is recommended when only moderate accuracy is required.

\section{The $k-\omega$ Model}

The $k-\omega$ model solves for turbulence intensity $(k)$ and dissipation rate per unit of turbulent kinetic energy $(\omega)$, where $\omega$ is determined through a conservation equation including experimentally determined functions, 
rather than direct calculation from the velocity field. The equations for $\omega$ treat it as a vorticity level or vortex fluctuation frequency. The model then produces turbulent viscosity as a function of $k$ and $\omega$ :

$$
\begin{gathered}
\rho \frac{\partial k}{\partial t}+\rho U_{j} \frac{\partial k}{\partial x_{j}}=\tau_{i j} \frac{\partial U_{i}}{\partial x_{j}}-\beta^{*} \rho k \omega+\frac{\partial}{\partial x_{j}}\left[\left(\mu+\sigma^{*} \mu^{\prime}\right) \frac{\partial k}{\partial x_{j}}\right] \\
\rho \frac{\partial \omega}{\partial t}+\rho U_{j} \frac{\partial \omega}{\partial x_{j}}=\alpha \frac{\omega}{k} \tau_{i j} \frac{\partial U_{i}}{\partial x_{j}}-\beta \rho \omega^{2}+\frac{\partial}{\partial x_{j}}\left[\left(\mu+\sigma \mu^{\prime}\right) \frac{\partial \omega}{\partial x_{j}}\right] \\
\mu^{\prime}=\frac{\rho k}{\omega} \\
\varepsilon=\beta^{*} \omega k
\end{gathered}
$$

The symbols $\alpha, \beta, \beta^{*}, \sigma$, and $\sigma^{*}$ represent constants set at $\alpha=5 / 9, \beta=3 / 40$, $\beta^{*}=9 / 100, \sigma=1 / 2$, and $\sigma^{*}=1 / 2 \cdot$ A wide variety of $k-\omega$ models have been generated and tested, with many different closure coefficients and corrections.

As with the $k-\varepsilon$ model, the latest versions of the $k-\omega$ model include correction terms to improve predictions in the low Reynolds number flow regions. The $k-\omega$ model typically produces $N u$ profiles with a local error of up to $30 \%$ of the experimental $N u$ value. It can produce better predictions of the turbulent length scale than the $k-\varepsilon$ model. The $k-\omega$ model can generate good predictions of flow properties in the wall jet, both in the sublayer and logarithmic region, without the need for damping functions. For a flow near a wall the boundary conditions are known - turbulent viscosity and the turbulent time scale are set to 0 . The value of $\omega$ at or near the wall cell may be set proportional to $v / y^{2}$, meaning the user can fully specify the turbulence conditions at the wall, unlike in the $k-\varepsilon$ model. Unfortunately, the $k-\omega$ model is sensitive to far-field boundary conditions, much more so than the $k-\varepsilon$ model. Park et al. [88] demonstrated some improved results using the $k-\omega$ equations but noted that at higher $\operatorname{Re}(25,100)$ the secondary $N u$ peaks appeared too far inward, as low as $50 \%$ of the experimentally measured value of $x / B$. The local levels of $N u$ were overpredicted by as much as $100 \%$ as the result of misplacing this peak. A comparative study by Heyerichs and Pollard [78] found that the $k-\omega$ model overpredicted $N u$ by up to $18 \%$ and generated a secondary peak closer to the jet center than found in experiment, but concluded that for the impinging jet problem it clearly outperformed the nine different implementations of the $k-\varepsilon$ model used in 
the study. The low-Re $k-\omega$ model gave good results by matching the shape of the experimental curves, but alternate formulations of the impinging jet CFD model using $k-\omega$ with wall functions gave poor results - they replaced the $k-\omega$ model with a cruder approximation in the very region where it gives the best results, overpredicting wall jet $N u$ by as much as $40 \%$. Chen and Modi [89] successfully applied the $k-\omega$ model for mass transfer at high $S c$, and claimed agreement within $10 \%$ of experimental results, given very high grid densities. The addition of cross-diffusion terms in various $k-\omega$ models have succeeded in reducing its sensitivity to far-field $\omega$ boundary conditions, a problem known to arise during use of the $k-\omega$ model for unconfined or partially confined flows.

\section{Realizability Limits}

In cases of high strain rates, the simple Boussinesq approximation may predict negative normal Reynolds stresses $\overline{\left(u_{i}^{2}\right.}<0$ [no summation], not physically possible) or excessively high Reynolds shear stresses $\left(\frac{\overline{u_{i}^{2} u_{j}^{2}}}{\overline{u_{i}^{2}}} \overline{\overline{u_{j}^{2}}}>1\right.$, no summation). The $k-\varepsilon, k-\omega$, and $v^{2} f$ models described herein have been commonly modified to use realizability limits to prevent these problems. A common fix is to allow variation in the model constant found in the turbulent viscosity equation, for example using

$$
C_{\mu}=\frac{1}{4.04+\sqrt{6} \cos \left(\frac{1}{3} \cos ^{-1}\left(\sqrt{6} \frac{S_{i j} S_{j k} S_{k i}}{\sqrt{S_{i j} S_{i j}}}\right)\right) \frac{k \sqrt{S_{i j} S_{i j}+\Omega_{i j} \Omega_{i j}}}{\varepsilon}}
$$

in a non-rotating reference frame, where $\Omega_{i j}=\frac{1}{2}\left(\frac{\partial U_{i}}{\partial x_{j}}-\frac{\partial U_{j}}{\partial x_{i}}\right)$ is the fluid rotation rate [90]. This value is then used directly in the equation $v^{\prime}=C_{\mu}\left(k^{2} / \varepsilon\right)$. Physical measurements have demonstrated variation in this "constant" in differing fluid flows. Other approaches put simple limits on time scales, length scales, strain rates, and/or terms including strain rates.

Abdon and Sunden [91] used nonlinear $k-\varepsilon$ and $k-\omega$ models with realizability constraints to model impinging jets. These model adjustments produced results closer to experimental data, with the realizable $k-\varepsilon$ model predicting $N u_{0}$ within $10 \%$ (within the experimental data scatter) and the realizable $k-\omega$ model overpredicting $N u_{0}$ by $20 \%$. Further studies with nonlinear versions of the $k-\varepsilon$ and $k-\omega$ models produced $N u$ profiles with errors equal to or greater than those of the standard linear models. The nonlinear models captured a secondary peak in $N u$ in the proper location at $r / D=2$, but overpredicted the $N u$ value by up to $50 \%$. Park and Sung [92] constructed a $k-\varepsilon-f_{\mu}$ model for low Re flows, where the turbulent viscosity 
damping function $\mathrm{f}_{\mu}$ incorporated terms to describe damping near the wall and terms to describe the equilibrium flow farther from the wall. With the inclusion of realizability limits on eddy viscosity they were able to improve the $N u$ profile predictions for $r / D<1.5$ to within $10-20 \%$ of experimental results, primarily by limiting overprediction of turbulent kinetic energy in the jet center. For the region of $r / D<1$ the model was tuned to predict the $N u$ profile within $15 \%$, giving a flat profile matching the experimental results. Given the slightly higher computational cost but potentially better results, realizability constraints are recommended for use in impinging jet flow CFD.

\section{Algebraic Stress Models}

Algebraic Stress Models (ASM) can provide a computationally inexpensive approach valid for some simple flows. The ASM models may be built with lower grid resolution in the wall region, which contributes to the computational efficiency. Rather than solve complete discretized differential transport equations this category of models solves algebraic equations which require fewer calculations. In cases where the turbulent velocity fluctuations change slowly compared to changes in the mean velocity, the Reynolds stresses can be approximated as algebraic functions of the dominant mean velocity derivatives in time and space. In a simple case, the ASM may use equations for calculating a length scale, which are particular to the problem geometry. This length scale is used to calculate turbulent viscosity, which is used with the Boussinesq approximation to determine the Reynolds stresses. Use of this approach requires enough advance knowledge of turbulent length and time scales for the problem of interest that the quantities may be calculated using algebraic equations, a potential source of large error. For simple geometries such as pipe flow or free jets, a set of equations for mixing length is available. Some ASMs simply drop the time and space derivatives of the Reynolds stresses from the equations, leaving only gradients of the mean flow velocity [74]. This approach assumes the turbulent convection and turbulent diffusion effects are either insignificant or are equal in magnitude. Unfortunately, for the impinging jet problem the boundary layer along the wall is not in equilibrium and this type of ASM is a crude approximation.

Comparative modeling by Funazaki and Hachiya showed that for an impingement problem their ASM overpredicted $N u$ by $\sim 30 \%$, outperforming $k-\varepsilon$ and RNG $k-\varepsilon$ models which typically showed $50-55 \%$ error [93]. Numerical work by Souris et al. [82] found that the ASM had better free-jet modeling than the $k-\varepsilon$ model, which generated better results in the wall region downstream. Both models overpredicted the centerline velocity decay, but the ASM overprediction was not as high. The error in jet width prediction of the ASM was as high as $35 \%$ close to the wall, better than the 
$59 \%$ error produced by the low Reynolds number version of the $k-\varepsilon$ model. In contrast, this ASM model used the standard logarithmic Law of the Wall and generated poor predictions of velocity profile in the region closest to the wall (within the first quarter of the wall-jet thickness), with high jet thicknesses (up to $65 \%$ error at $r / D=2.5$ ) and wall jet velocity magnitudes as much as $45 \%$ below experiment. These results do not mean the ASM correctly described the impinging flow, but rather the $k-\varepsilon$ model resulted in gross errors, larger than the errors present when using the ASM. The ASM may be better than a number of poor $k-\varepsilon$ models, but is not recommended as it does not yield accuracies that are commensurate with the required computational effort.

\section{Complete RSM Modeling}

The SMC Reynolds Stress Model (RSM), also known as the Reynolds Stress Transport Model (RSTM), tracks all six independent components of the Reynolds stress tensor, accounting for production, diffusive transport, dissipation, and turbulent transport. Common implementations require a number of constants to resolve terms such as a pressure-strain term and terms in the turbulence dissipation equation. Because the RSM model does not assume isotropic stresses, it can give much better predictions of fluid behavior in turning or rotating flows that those of the two-equations models. RSM modeling of impinging jets by Demuren [94] showed velocity predictions ranging from -40 to $+40 \%$ of the experimentally measured velocities, and Reynolds stress errors of over $100 \%$, which was attributed to a need for an extremely dense grid (denser than that utilized in the modeling). Craft et al. [75] presented computed centerline wall-normal r.m.s. turbulent velocity levels, which matched within $25 \%$ of experiment at $H / D=2$, but had errors as large as $80-100 \%$ for $H / D=6$. The RSM can predict the occurrence of a secondary peak in $\mathrm{Nu}$, but not necessarily at the correct location [95]. This shows that although the various RSM implementations preserve all the Reynolds stress terms, they still use approximation equations based on a number of assumptions. That is, they eliminate the isotropy assumptions which yield the two-equation models but still rely upon other empirically generated equations to predict the stresses and do not give a "perfect" solution. Given the high computational cost compared to the eddy-viscosity models, these results are disappointing and the RSM is not recommended as an alternative.

\section{The $v^{2}-f$ Model}

Durbin's $v^{2}-f$ model, also known as the "normal velocity relaxation model," has shown some of the best predictions to date, with calculated $\mathrm{Nu}$ 
values falling within the spread of experimental data $[25,96]$. The $v^{2}-f$ model uses an eddy viscosity to increase stability (rather than using a full RSM) with two additional differential equations beyond those of the $k-\varepsilon$ model, forming a four-equation model. It uses the turbulent stress normal to the streamlines (referred to as $\overline{v^{2}}$ ) to determine the turbulent eddy viscosity, rather than the scalar turbulence intensity used in the $k-\varepsilon$ model. It incorporates upper and lower limits on the turbulent time and length scales. The " $f$ " term in the model name refers to an included function to capture the effects of walls upon variations in $\overline{v^{2}}$. The additional equations are defined as

$$
\begin{aligned}
& \frac{D k}{D t}=\frac{\partial}{\partial x_{j}}\left[\left(v+v^{\prime}\right) \frac{\partial k}{\partial x_{j}}\right]+2 v^{\prime} S_{i j} S_{i j}-\varepsilon \\
& v^{\prime}=C_{\mu} \overline{v^{2}} T_{\text {scale }} \\
& \frac{D \varepsilon}{D t}=\frac{c^{\prime}{ }_{\varepsilon 1} 2 v^{\prime} S_{i j} S_{i j}-c_{\varepsilon 2} \varepsilon}{T_{\text {scale }}}+\frac{\partial}{\partial x_{j}}\left[\left(v+\frac{v^{\prime}}{\sigma_{\varepsilon}}\right) \frac{\partial \varepsilon}{\partial x_{j}}\right] \\
& \frac{D \overline{v^{2}}}{D t}=k f_{\text {wall }}-\overline{v^{2}} \frac{\varepsilon}{k}+\frac{\partial}{\partial x_{j}}\left[\left(v+v^{\prime}\right) \frac{\partial \overline{v^{2}}}{\partial x_{j}}\right] \\
& f_{\text {wall }}-L_{\text {scale }}^{2} \frac{\partial}{\partial x_{j}} \frac{\partial f}{\partial x_{j}}=\frac{\left(C_{1}-1\right)\left(\frac{2}{3}-\frac{\overline{v^{2}}}{k}\right)}{T_{\text {scale }}}+\frac{C_{2} 2 v^{\prime} S_{i j} S_{i j}}{k} \\
& L_{\text {scale }}=C_{L} \max \left(\min \left(\frac{k^{\frac{3}{2}}}{\varepsilon}, \frac{1}{\sqrt{3}} \frac{k^{\frac{3}{2}}}{\overline{v^{2}} C_{\mu} \sqrt{2 S_{i j} S_{i j}}}\right), C_{\eta}\left(\frac{v^{3}}{\varepsilon}\right)^{\frac{1}{4}}\right) \\
& T_{\text {scale }}=\min \left(\max \left(\frac{k}{\varepsilon}, 6 \sqrt{\frac{v}{\varepsilon}}\right), \frac{\alpha}{\sqrt{3}} \frac{k}{\overline{v^{2}} C_{\mu} \sqrt{2 S_{i j} S_{i j}}}\right) \\
& c_{\varepsilon 1}^{\prime}=1.44\left(1+0.045 \sqrt{\frac{k}{v^{2}}}\right)
\end{aligned}
$$


where $C_{\mu}=0.19, c_{\varepsilon 2}=1.9, \sigma_{\varepsilon}=1.3, C_{1}=1.4, C_{2}=0.3, C_{\eta}=70.0$, $C_{L}=0.3$, and $\alpha=0.6$. Similar equations exist for predicting the transport of a scalar (e.g. thermal energy) with a $P r^{\prime}$ as a function of $v$ and $v^{\prime}$.

As with the $k-\omega$ model, the $v^{2}-f$ model requires a dense wall grid. In some cases the $v^{2}-f$ model has been shown to predict realistic levels of turbulence in the decelerating jet core, but excessive turbulence levels in the shearing flow outside the core and in the wall jet [97]. Despite this difficulty and its moderately high computational cost, it is acknowledged as one of the best predictors of $N u$ distribution. It has an advantage over the standard $k-\varepsilon$ series of models because it can predict the occurrence, position, and magnitude of the secondary $N u$ peak for low $H / D$. This model is highly recommended for the impinging jet problem, and its moderate computational cost is offset by its ability to closely match experimental results.

\section{Hybrid Modeling}

The impinging jet problem has at least three distinct flow regions with distinct flow physics. The computationally efficient two-equation models discussed previously are adjusted to perform best in one physical situation, with closure equations and coefficients based on a set of simple turbulent flows. Application to alternate geometries demonstrates the weakness of the model. No simple model has produced the ultimate answer, but by combining two or more models the CFD code can produce a compromise of sorts. For example, the model may calculate in which region the flow lies (free jet, stagnation, or wall jet) and use a model successfully tested for that particular region. The solution from the multiple models in multiple regions must then be combined at the boundaries in a smooth fashion to produce a Hybrid turbulence model. In doing so, the CFD program may utilize the strengths and minimize the weaknesses of each model.

Menter's Shear Stress Transport (SST) model is one of the most successful Hybrid models [98]. The SST model combines the $k-\omega$ model near the wall and the $k-\varepsilon$ model farther from the wall to utilize the strengths of each. Smooth transition between the two is accomplished by use of a blending or weighting function based upon distance from the wall, formulated by Menter as

$$
\begin{gathered}
F_{1}=\tanh \left[\left(\min \left\{\max \left[\frac{\sqrt{k}}{0.09 \omega y}, \frac{500 v}{y^{2} \omega}\right], \frac{4 \rho \sigma_{\omega 2} k}{C D_{k \omega} y^{2}}\right\}\right)^{4}\right] \\
C D_{k \omega}=\max \left[2 \rho \sigma_{\omega 2} \frac{1}{\omega} \frac{\partial k}{\partial x_{j}} \frac{\partial \omega}{\partial x_{j}}, 10^{-20}\right]
\end{gathered}
$$


where $\sigma_{\omega 2}=0.856$, an empirical constant associated with the transformed $k-\varepsilon$ model. Menter's SST model uses a variant equation for determining turbulent viscosity based upon

$$
v^{\prime}=\frac{0.31 k}{\max \left(0.34 \omega, \Omega\left[\max \left(\frac{2 \sqrt{k}}{0.09 \omega y}, \frac{500 v}{y^{2} \omega}\right)\right]^{2}\right)}
$$

with the goal of improving predictions of turbulence in adverse pressure gradients. The SST model still requires a finely spaced mesh near the wall to produce accurate results. Validation comparisons by Esch et al. [77] showed $\mathrm{Nu}$ predictions within $20 \%$ of experimental results, and a $N u$ profile no farther than $5 \%$ above or below the profile predicted by the $v^{2}-f$ model. The SST model also predicted mean velocities well, clearly better than the $k-\varepsilon$ model and within the uncertainty of the experimental measurements. This indicates the SST model may provide predictions as good as those of the $v^{2}-f$ model but at a lower computational cost, and it is recommended for this reason.

\section{Conclusions Regarding Model Performance}

Ultimately, all CFD results should be validated by comparison to reliable experimental results and to determine overall model error in predicting the real situation. The model must match the experimental conditions, including all of the geometry, fluid entry and exit conditions, and target surface properties. This matching must include not only the domain boundary average velocities, pressures, and temperatures, but also their turbulent components.

Experiments to measure turbulence levels and transfer coefficients continue. While many of these explore new geometries and provide more accurate measurements, some of these experiments reproduce the results of earlier work. Sufficient data exist for design of impinging jet devices with simple geometries, such as a single round or slot nozzle, or a simple jet array at large spacing. The most useful new experiments explore new geometries, in particular the less-than-ideal geometries required in functional hardware.

A large number of informative studies have been conducted using the $k-\varepsilon$ model to attempt to predict the heat/mass transfer of impinging jets, with only limited success. Examination of RANS numerical modeling techniques showed that even with high-resolution grids, the various implementations of the $k-\varepsilon, k-\omega, \mathrm{RSM}$, and ASM models give large errors compared to experimental data sets. The $v^{2}-f$ and SST models can produce better predictions of fluid properties in impinging jet flows and are recommended as the best compromise between solution speed and accuracy. Table III summarizes the relative performance of the various models, rated 
TABLE III

Comparison of CFD Turbulence Models Used Impinging Jet Problems

\begin{tabular}{|c|c|c|c|}
\hline $\begin{array}{l}\text { Turbulence } \\
\text { model }\end{array}$ & $\begin{array}{l}\text { Computational cost } \\
\text { (time required) }\end{array}$ & $\begin{array}{l}\text { Impinging jet transfer } \\
\text { coefficient prediction }\end{array}$ & $\begin{array}{l}\text { Ability to predict } \\
\text { secondary peak }\end{array}$ \\
\hline$k-\varepsilon$ & $\begin{array}{l}\star \star \star \star \\
\text { Low cost }\end{array}$ & $\begin{array}{l}\star \\
\text { Poor: } N u \text { errors of } \\
\quad 15-60 \%\end{array}$ & $\begin{array}{l}\star \\
\text { Poor }\end{array}$ \\
\hline$k-\omega$ & $\begin{array}{l}\star \star \star \star \\
\text { Low-moderate }\end{array}$ & $\begin{array}{l}\star \star \\
\text { Poor-fair: anticipate } \\
\quad N u \text { errors of at least } \\
\quad 10-30 \%\end{array}$ & $\begin{array}{l}\star \star \\
\text { Fair: may have } \\
\quad \text { incorrect location } \\
\quad \text { or magnitude }\end{array}$ \\
\hline $\begin{array}{l}\text { Realizable } k-\varepsilon \\
\quad \text { and other } k-\varepsilon \\
\text { variations }\end{array}$ & $\begin{array}{l}\star \star \star \star \\
\text { Low }\end{array}$ & $\begin{array}{l}\star \star \\
\text { Poor-fair: expect } N u \\
\quad \text { errors of at } 15-30 \%\end{array}$ & $\begin{array}{l}\star \star \\
\text { Poor-fair: may have } \\
\quad \text { incorrect location } \\
\text { or magnitude }\end{array}$ \\
\hline \multirow{2}{*}{$\begin{array}{l}\text { Algebraic stress } \\
\text { model }\end{array}$} & $\star \star \star \star$ & $\star \star$ & $\star$ \\
\hline & Low & $\begin{array}{l}\text { Poor-fair: anticipate } \\
\quad N u \text { errors of at least } \\
10-30 \%\end{array}$ & Poor \\
\hline \multirow{2}{*}{$\begin{array}{l}\text { Reynolds stress } \\
\text { model (full } \\
\text { SMC) }\end{array}$} & $\star \star$ & $\star$ & $\star \star$ \\
\hline & Moderate-high & $\begin{array}{l}\text { Poor: anticipate } N u \\
\quad \text { errors of } 25-100 \%\end{array}$ & $\begin{array}{l}\text { Fair: may have } \\
\text { incorrect location } \\
\text { or magnitude }\end{array}$ \\
\hline $\begin{array}{l}\text { Shear stress } \\
\text { transport }\end{array}$ & $\star \star \star$ & $\star \star \star$ & $\star \star$ \\
\hline $\begin{array}{l}\text { (SST), hybrid } \\
\text { method }\end{array}$ & Low-moderate & $\begin{array}{l}\text { Good: typical } N u_{0} \\
\quad \text { errors of } 20-40 \%\end{array}$ & Fair \\
\hline$v^{2} f$ & $\begin{array}{l}\star \star \star \\
\text { Moderate }\end{array}$ & $\begin{array}{l}\star \star \star \star \\
\text { Excellent: anticipate } N u \\
\quad \text { errors of } 2-30 \%\end{array}$ & $\begin{array}{l}\star \star \star \star \\
\text { Excellent }\end{array}$ \\
\hline $\begin{array}{l}\text { DNS/LES time- } \\
\text { variant } \\
\text { models }\end{array}$ & $\begin{array}{l}\text { Æxtremely high } \\
\quad \text { (DNS available } \\
\quad \text { for low Re only) }\end{array}$ & $\begin{array}{l}\star \star \star \star \\
\text { Good-excellent }\end{array}$ & $\begin{array}{l}\star \star \star \star \\
\text { Good-excellent }\end{array}$ \\
\hline
\end{tabular}

[ $\star$ indicating undesirable model characteristics, to $\star \star \star \star$ indicating excellent model characteristics.] 
qualitatively on a scale from " $\star$ " indicating undesirable model characteristics, to " $\star \star \star \star$ "indicating excellent model characteristics.

The actual computational cost will of course vary with model complexity and computing power. With the computing resources of a single desktop computer available at the time of writing, typically $3 \mathrm{GHz}$ processors, for a high-resolution two-dimensional problem the steady time-averaged eddy viscosity models $\left(k-\varepsilon, k-\omega\right.$, SST, $\left.v^{2}-f\right)$ will have computation times of a few hours (3-12). In comparison, the more complex RSM could take 4-40 h depending on how smoothly the model converges. Based on recent work, unsteady LES models have computation times at least two orders of magnitude higher; a well-resolved three-dimensional LES impinging jet model could take weeks to provide a solution. As processing power continues to grow and parallel computation becomes more widely available, these calculation times will decrease accordingly.

\section{Conclusions}

The review of recent impinging jet research publications identified a series of engineering research tasks important to improving the design and resulting performance of impinging jets:

(1) Clearly resolve the physical mechanisms by which multiple peaks occur in the transfer coefficient profiles, and clarify which mechanism(s) dominate in various geometries and Reynolds number regimes.

(2) Develop a turbulence model, and associated wall treatment if necessary, that reliably and efficiently provides time-averaged transfer coefficients. Given the varied and inaccurate results of the alternatives, the SST and $v^{2}-f$ models offer the best results for the least amount of computation time. Even so, they are imperfect. The improved turbulence model must correctly predict the jet spreading, turbulent flow effects in the stagnation region, and turbulent flow properties along the wall. Though inelegant, the solution by means of a hybrid model would serve this purpose if it included a turbulence model carefully adjusted to properly simulate the turning anisotropic flow field in the stagnation region.

(3) Develop alternate nozzle and installation geometries that provide higher efficiency, meaning improved $N u$ profiles at either a set flow or set blower power. Present work in swirling jets, pulsed jets, crossshaped nozzles, tab nozzles, coaxial nozzles, and other geometries represent a small sample of the practical possibilities. In addition to simply raising the average $N u$ value, it is of practical use to design and test hardware to produce more uniform $N u$ patterns. 
(4) Further explore the effects of jet interference in jet array geometries, both experimentally and numerically. This includes improved design of exit pathways for spent flow in array installations.

\section{Appendix: Correlation Reference}

\section{A. Correlation List}

The following correlations and equations for predicting $N u$ are provided as a reference for designers of impinging jet devices. In addition to providing design equations, they provide an example of typical $R e$ ranges and configurations studied most frequently. The nomenclature is adjusted to maintain consistency with this review. Table A.1 summarizes the conditions.

Impingement Device/Nozzle Type: Slot Jet, Short Contoured Nozzle on Convex Surface

Source: Chan et al. [63]

Range of validity: Re from 5,600 to $13,200, H / B$ from 2 to $10, S / B$ from 0 to 13.6

\section{Equation ( $s$ ):}

for $H / B$ from 2 to $8: N u_{0}=0.514 R e_{B}{ }^{0.50}(H / B)^{0.124}$

for $H / B$ from 8 to $10: N u_{0}=1.175 R e_{B}^{0.54}(H / B)^{-0.401}$

for $H / B$ from 2 to $8: N u_{a v g}=0.514 \operatorname{Re}_{B}{ }^{0.50}(H / B)^{0.124}[1.068-(0.31 / 2)(S / B)$ $+(0.079 / 3)(S / B)^{2}-(0.01154 / 4)(S / B)^{3}+\left(8.133 \times 10^{-4} / 5\right)(S / B)^{4}$ $\left.-\left(2.141 \times 10^{-5} / 6\right)(S / B)^{5}\right]$

for $H / B$ from 8 to 10: $N u_{\text {avg }}=1.175 \operatorname{Re}_{B}{ }^{0.54}(H / B)^{-0.401}[1.016-(0.393 / 2)$ $(S / B)+(0.1 / 3)(S / B)^{2}-(0.01323 / 4)(S / B)^{3}+\left(8.503 \times 10^{-4} / 5\right)(S / B)^{4}$ $\left.-\left(2.089 \times 10^{-5} / 6\right)(S / B)^{5}\right]$

$S=$ maximum lateral position on target surface (circumferential distance) $B=$ slot jet nozzle width

Impingement Device/Nozzle Type: Array of Round Jets, Orifice Nozzles

Source: Florschuetz et al. [33]

Range of validity:

$R e$ from 2,500 to $70,000, U_{\text {crossflow }} / U_{\text {jet }}$ from 0 to $0.8, H / D$ from 1 to 3 $p_{x}=p_{\text {jet streamwise }} / D$ from 5 to 15 for inline arrays, from 5 to 10 for staggered arrays,

$p_{y}=p_{\text {jet spanwise }} / D$ from 4 to $8, p_{x} / p_{y}$ from 0.625 to 3.75 
TABLE A.1

Correlation list

\begin{tabular}{|c|c|c|c|}
\hline Source & Nozzle type & Provides & $\begin{array}{c}\text { Reynolds number, nozzle } \\
\text { height range }\end{array}$ \\
\hline Chan et al. [63] & $\begin{array}{l}\text { Single slot nozzle (convex } \\
\text { target), contoured }\end{array}$ & $N u_{0}, N u_{\text {avg }}$ & $\begin{array}{l}5,600 \leqslant R e \leqslant 13,200 \\
2 \leqslant H / B \leqslant 10\end{array}$ \\
\hline $\begin{array}{l}\text { Florschuetz et al. } \\
\text { [33] }\end{array}$ & $\begin{array}{l}\text { Array of round nozzles, } \\
\text { orifice }\end{array}$ & $N u_{\text {avg }}$ & $\begin{array}{l}2,500 \leqslant R e \leqslant 70,000 \\
1 \leqslant H \mid D \leqslant 3\end{array}$ \\
\hline $\begin{array}{l}\text { Goldstein and Seol } \\
\text { [99] }\end{array}$ & $\begin{array}{l}\text { Row of round nozzles } \\
\text { (square orifice) }\end{array}$ & $N u_{\text {avg }}$ & $\begin{array}{l}10,000 \leqslant R e \leqslant 40,000 \\
0 \leqslant H / D \leqslant 6\end{array}$ \\
\hline $\begin{array}{l}\text { Goldstein and } \\
\text { Behbahani } \\
{[100]}\end{array}$ & $\begin{array}{l}\text { Single round nozzle, } \\
\text { orifice }\end{array}$ & $N u_{\text {avg }}$ & $\begin{array}{l}34,000 \leqslant R e \leqslant 121,300 \\
H / D=6 \text { or } 12\end{array}$ \\
\hline $\begin{array}{l}\text { Goldstein et al. } \\
\quad[10]\end{array}$ & $\begin{array}{l}\text { Single round nozzle, } \\
\text { orifice }\end{array}$ & $N u_{\text {avg }}$ & $\begin{array}{l}61,000 \leqslant R e \leqslant 124,000 \\
6 \leqslant H / D \leqslant 12\end{array}$ \\
\hline $\begin{array}{l}\text { Gori and Bossi } \\
\text { [48] }\end{array}$ & $\begin{array}{l}\text { Single slot nozzle (on } \\
\text { cylinder), pipe }\end{array}$ & $N u_{\text {avg }}$ & $\begin{array}{l}4,000 \leqslant R e \leqslant 20,000 \\
2 \leqslant H \mid B \leqslant 12\end{array}$ \\
\hline $\begin{array}{l}\text { Huang and El- } \\
\text { Genk [101] }\end{array}$ & Single round nozzle, pipe & $N u_{\text {avg }}$ & $\begin{array}{l}6,000 \leqslant R e \leqslant 60,000 \\
1 \leqslant H / B \leqslant 12\end{array}$ \\
\hline $\begin{array}{l}\text { Huber and } \\
\quad \text { Viskanta [30] }\end{array}$ & $\begin{array}{l}\text { Array of round nozzles, } \\
\quad \text { orifice }\end{array}$ & $N u_{\text {avg }}$ & $\begin{array}{l}3,400 \leqslant R e \leqslant 20,500 \\
0.25 \leqslant H / D \leqslant 6\end{array}$ \\
\hline $\begin{array}{l}\text { Lytle and Webb } \\
\text { [102] }\end{array}$ & Single round nozzle, pipe & $N u_{0}$ and $N u_{\text {avg }}$ & $\begin{array}{l}3,600 \leqslant R e \leqslant 27,600 \\
0.1 \leqslant H / D \leqslant 1\end{array}$ \\
\hline Martin [2] & $\begin{array}{l}\text { Single round nozzle, } \\
\text { orifice or pipe }\end{array}$ & $N u_{\text {avg }}$ & $\begin{array}{l}2,000 \leqslant R e \leqslant 400,000 \\
2 \leqslant H / D \leqslant 12\end{array}$ \\
\hline Martin [2] & $\begin{array}{l}\text { Single slot nozzle, orifice } \\
\text { or pipe }\end{array}$ & $N u_{\text {avg }}$ & $\begin{array}{l}3,000 \leqslant R e \leqslant 90,000 \\
2 \leqslant H /(2 B) \leqslant 10\end{array}$ \\
\hline Martin [2] & $\begin{array}{l}\text { Array of round nozzles, } \\
\text { orifice or pipe }\end{array}$ & $N u_{\text {avg }}$ & $\begin{array}{l}2,000 \leqslant R e \leqslant 100,000 \\
2 \leqslant H / D \leqslant 12\end{array}$ \\
\hline Martin [2] & $\begin{array}{l}\text { Array of slot nozzles, } \\
\text { orifice or pipe }\end{array}$ & $N u_{\text {avg }}$ & $\begin{array}{l}1,500 \leqslant R e \leqslant 40,000 \\
1 \leqslant H /(2 B) \leqslant 40\end{array}$ \\
\hline $\begin{array}{l}\text { Mohanty and } \\
\text { Tawfek [103] }\end{array}$ & $\begin{array}{l}\text { Single round nozzle, pipe } \\
\text { and tapered nozzle }\end{array}$ & $N u_{0}$ & $\begin{array}{l}4,860 \leqslant R e \leqslant 34,500 \\
6 \leqslant H / D \leqslant 58\end{array}$ \\
\hline San and Lai [27] & $\begin{array}{l}\text { Array of round nozzles } \\
\text { (staggered), orifice }\end{array}$ & $N u_{0}$ & $\begin{array}{l}10,000 \leqslant R e \leqslant 30,000 \\
2 \leqslant H / D \leqslant 5\end{array}$ \\
\hline Tawfek [104] & $\begin{array}{l}\text { Single round nozzle, pipe } \\
\text { and tapered nozzle }\end{array}$ & $N u_{\text {avg }}$ & $\begin{array}{l}3,400 \leqslant R e \leqslant 41,000 \\
6 \leqslant H / D \leqslant 58\end{array}$ \\
\hline $\begin{array}{c}\text { Wen and Jang } \\
{[105]}\end{array}$ & Single round nozzle, pipe & $N u_{\text {avg }}$ & $\begin{array}{l}750 \leqslant R e \leqslant 27,000 \\
3 \leqslant H \mid D \leqslant 16\end{array}$ \\
\hline
\end{tabular}




\section{Equations:}

$\mathrm{p}_{x}=\mathrm{p}_{\text {jet streamwise }} / \mathrm{D}$

$\mathrm{p}_{y}=\mathrm{p}_{\text {jet spanwise }} / \mathrm{D}$

$U_{\text {crossflow }}=$ magnitude of crossflow velocity in channel (density-weighted)

$U_{\text {jet }}=$ magnitude of jet exit velocity (density-weighted)

$$
\begin{aligned}
& N u=A \operatorname{Re}^{m}\left\{1-B\left[(H / D)\left(U_{\text {crossflow }} / U_{\text {jet }}\right)\right]^{n}\right\} \operatorname{Pr}^{1 / 3} \\
& A_{\text {inline }}=1.18\left(p_{x}^{-0.944}\right)\left(p_{y}^{-0.642}\right)\left([H / D]^{0.169}\right) \\
& m_{\text {inline }}=0.612\left(p_{x}^{.059}\right)\left(p_{y}^{.032}\right)\left([H / D]^{-0.022}\right) \\
& B_{\text {inline }}=0.437\left(p_{x}^{-0.095}\right)\left(p_{y}^{-0.219}\right)\left([H / D]^{0.275}\right) \\
& n_{\text {inline }}=0.092\left(p_{x}^{-0.005}\right)\left(p_{y}^{0.599}\right)\left([H / D]^{1.04}\right) \\
& A_{\text {staggered }}=1.87\left(p_{x}^{-0.771}\right)\left(p_{y}^{-0.999}\right)\left([H / D]^{-0.257}\right) \\
& m_{\text {staggered }}=0.571\left(p_{x}^{.028}\right)\left(p_{y}^{.092}\right)\left([H / D]^{0.039}\right) \\
& B_{\text {staggered }}=1.03\left(p_{x}^{-0.243}\right)\left(p_{y}^{-0.307}\right)\left([H / D]^{0.059}\right) \\
& n_{\text {staggered }}=0.442\left(p_{x}^{.098}\right)\left(p_{y}{ }^{-0.003}\right)\left([H / D]^{0.304}\right)
\end{aligned}
$$

Impingement Device/Nozzle Type: Row of Round Jets, Square-Edged Orifice Nozzles

Source: Goldstein and Seol [99]

Range of validity: for $H / D$ from 2 to $6, p_{\text {jet }} / D$ from 4 to $8, H / D$ from 0 to 6 , $R e$ from 10,000 to 40,000 , orifice height $l=D$

Equation $(s)$ :

$$
N u_{\text {avg }}=\frac{2.9 \exp \left(-0.09(H / D)^{1.4}\right) R e^{0.7}}{22.8+\left(p_{\text {jet }} / D\right) \sqrt{H / D}}
$$

Impingement Device/Nozzle Type: Single Round Jet, Orifice Nozzle

Source: Goldstein and Behbahani [100]

Range of validity: $r / D$ from 0.5 to $32, R e=\sim 34,000$ to $121,300, L / D=6$ or 12

Equation $(s)$ :

for $L / D=6, N u_{\text {avg }}=R e^{0.6} /\left[3.329+0.273\left(r_{\max } / D\right)^{1.3}\right]$

for $L / D=12, N u_{\text {avg }}=R e^{0.6} /\left[4.577+0.4357\left(r_{\max } / D\right)^{1.14}\right]$ 
Impingement Device/Nozzle Type: Single Round Jet, Orifice Nozzle

Source: Goldstein, Behbahani, and Heppelmann [10]

Range of validity: Re from 61,000 to $124,000, H / D$ from 6 to 12

Equation ( $s$ ):

target at constant temperature : $N u_{\text {avg }}=\frac{24-|(H / D)-7.75|}{533+44(r / D)^{1.285}} R e^{0.76}$

target at constant heat flux : $N u_{\text {avg }}=\frac{24-|H / D-7.75|}{533+44(r / D)^{1.394}} R e^{0.76}$

Impingement Device/Nozzle Type: Single Slot Jet, Pipe Nozzle, Normal to a Cylindrical Target

Source: Gori and Bossi [48]

Range of validity: $D / B$ from 1 to 4, Re from 4,000 to $20,000, H / B$ from 2 to 12

Equation ( $s)$ :

for $H / B$ from 2 to 8: $N u_{\text {avg }}=0.0516(H / B)^{0.179}(D / B)^{0.214} \operatorname{Re}^{0.753} \operatorname{Pr}^{0.4}$

for $H / B$ from 8 to 12 : $N u_{\text {avg }}=0.0803(H / B)^{-0.205}(D / B)^{0.162} \operatorname{Re}^{0.800} \operatorname{Pr}^{0.4}$

Impingement Device/Nozzle Type: Single Slot Jet, Pipe Nozzle

Source: Huang and El-Genk [102]

Range of validity: Re from 6000 to $60,000, H / B$ from 1 to 12

Equation ( $s$ ):

$N u_{\text {avg }}=\operatorname{Re}^{0.76} \operatorname{Pr}^{0.42}\left[a+b(H / D)+c(H / D)^{2}\right]$

$a=\left(1 \times 10^{-4}\right)\left(506+13.3\left[r_{\max } / D\right]-19.6\left[r_{\max } / D\right]^{2}+2.41\left[r_{\max } / D\right]^{3}\right.$

$\left.-0.0904\left[r_{\text {max }} / D\right]^{4}\right)$

$b=\left(1 \times 10^{-4}\right)\left(32-24.3\left[r_{\max } / D\right]+6.53\left[r_{\max } / D\right]^{2}-0.694\left[r_{\max } / D\right]^{3}\right.$

$\left.+0.0257\left[r_{\max } / D\right]^{4}\right)$

$c=\left(-3.85 \times 10^{-4}\right)\left(1.147+\left[r_{\max } / D\right]\right)^{-0.0904}$ 
Impingement Device/Nozzle Type: Array of Round Jets, Square Array, Orifice Nozzles, Confined Jets, Exit

Source: Huber and Viskanta [30]

Range of validity: $H / D$ from 0.25 to 6 , spacing $p_{\text {jet }} / D$ from 4 to $8, R e$ from 3,400 to 20,500

Equation $(s)$ :

$$
N u_{\text {avg }}=0.285 \operatorname{Re}^{0.71} \operatorname{Pr}^{0.33}(H / D)^{-0.123}\left(p_{\text {jet }} / D\right)^{-0.725}
$$

Impingement Device/Nozzle Type: Single Round Jet, Pipe Nozzle

Source: Lytle and Webb [102]

Range of validity: $H / D$ from 0.1 to $1, N u_{0}$ equations for $R e$ from 3,700 to $30,000, N u_{a v g}$ equations for $R e$ from 3,600 to 27,600

Equation $(s)$ :

for $H / D \leqslant 1.0: N u_{0}=0.726 R e^{0.53}(H / D)^{-0.191}$

for $H / D \leqslant 0.5: N u_{0}=0.663 R e^{0.53}(H / D)^{-0.248}$

for $H / D \leqslant 0.25: N u_{0}=0.821 R e^{0.5}(H / D)^{-0.288}$

Radial peaks in $N u$ are located at: $r_{\max } / D=0.188 R e^{0.241}(H / D)^{0.224}$

$N u_{\text {avg }}$ out to $r / D=1: N u_{\text {avg }}=0.424 R e^{0.57}(H / D)^{-0.33}$

$N u_{\text {avg }}$ out to $r / D=2: N u_{\text {avg }}=0.150 R e^{0.67}(H / D)^{-0.36}$

Impingement Device/Nozzle Type: Single Round Nozzle

Source: Martin [2]

Range of validity: $2,000<R e<400,000,0.004 \leqslant f \leqslant 0.04,2.5 \leqslant r / D \leqslant 7.5$, and $2 \leqslant H / D \leqslant 12$.

Equation (s):

$$
N u_{\text {avg }}=\operatorname{Pr}^{0.42} \frac{D}{r} \frac{1-1.1 D / r}{1+0.1(H / D-6) D / r} F
$$

for $2,000<R e<30,000, F=1.36 R e^{0.574}$

for $30,000<R e<120,000, F=0.54 R e^{0.667}$

for $120,000<R e<400,000, F=0.151 R e^{0.775}$ 
Impingement Device/Nozzle Type: Single Slot Nozzle

Source: Martin [2]

Range of validity: $3000<R e<90,000,0.01 \leqslant f \leqslant 0.125,2 \leqslant x / S \leqslant 25$, and $2 \leqslant H / S \leqslant 10$.

Equation ( $s$ ):

$$
N u_{\text {avg }}=\operatorname{Pr}^{0.42} \frac{1.53}{(x / S)+(H / S)+1.39} \operatorname{Re}^{\left(0.695-\left[x / S+(H / S)^{1.33}+3.06\right]^{-1}\right)},
$$

$S=$ twice slot width $=$ nozzle hydraulic diameter

Impingement Device/Nozzle Type: Round Nozzle Array

Source: Martin [2]

Range of validity: $2,000<R e<100,000,0.004 \leqslant f \leqslant 0.04$, and $2 \leqslant H / D \leqslant 12$.

Equation (s):

$$
\begin{gathered}
N u_{\text {avg }}=\operatorname{Pr}^{0.42}(K)(G)(F) \\
K=\left(1+\left(\frac{H / D}{0.6 / \sqrt{f}}\right)^{6}\right)^{-0.05} \\
G=2 \sqrt{f} \frac{1-2.2 \sqrt{f}}{1+0.2((H / D)-6) \sqrt{f}} \\
F=0.5 \operatorname{Re}^{2 / 3}
\end{gathered}
$$

Equations are for a developed jet. For a sharp orifice jet, give the value of a contraction coefficient (discharge coefficient) and

- Multiply diameter $D$ by square root of contraction coefficient;

- Multiply $f$ by contraction coefficient;

- Divide $U$ by contraction coefficient;

- Divide $R e$ by square root of contraction coefficient;

- Divide $\operatorname{Pr}^{0.42}$ by square root of contraction coefficient. 
Impingement Device/Nozzle Type: Slot Nozzle Array

Source: Martin [2]

Range of validity: $1,500<R e<40,000,0.008 \leqslant f \leqslant 2.5 f_{0}$, and $1 \leqslant H / S \leqslant 40$.

Equation (s):

$$
\begin{gathered}
N u_{\text {avg }}=\operatorname{Pr}^{0.42} \frac{2}{3} f_{0}^{3 / 4}\left(\frac{2 R e}{f / f_{0}+f_{0} / f}\right)^{2 / 3} \\
f_{0}=\left[60+4(H / S-2)^{2}\right]^{-1 / 2}
\end{gathered}
$$

$S=$ twice slot width $=$ nozzle hydraulic diameter

Equations are for a developed jet. For a sharp orifice jet, give the value of a contraction coefficient (discharge coefficient) and

- Multiply both $S$ and $f$ by contraction coefficient;

- Divide $U$ by contraction coefficient;

- Divide $\operatorname{Pr}^{0.42}$ by square root of contraction coefficient.

Impingement Device/Nozzle Type: Single Round Jet, Pipe and Tapered Nozzle

Source: Mohanty and Tawfek [103]

Range of validity: $H / D$ from 6 to 41, Re from 4,860 to 34,500 (varies by case, see the following)

Equation ( $s$ ):

for $H / D$ from 10 to $16.7, \operatorname{Re}$ from 4,860 to 15,300 :

$N u_{0}=0.15 R e^{0.701}(H / D)^{-0.25}$

for $H / D$ from 20 to $25, R e$ from 4,860 to 15,300 :

$N u_{0}=0.17 R e^{0.701}(H / D)^{-0.182}$

for $H / D$ from 6 to $58, R e$ from 6,900 to 24,900 :

$N u_{0}=0.388 R e^{0.696}(H / D)^{-0.345}$

for $H / D$ from 9 to $41.4, R e$ from 7,240 to 34,500 :

$N u_{0}=0.615 R e^{0.67}(H / D)^{-0.38}$ 
Impingement Device/Nozzle Type: Array of Round Jets, Staggered, Orifice Nozzles

Source: San and Lai [27]

Range of validity: Re from 10,000 to $30,000, H / D$ from 2 to $5, p_{j e t} / D$ from 4 to 16 , orifice depth $l=D$

Equation ( $s$ ):

For $H / D$ from 2 to $3.5, p_{\text {jet }} / D$ from 6 to 16 , $N u_{0}=\left(p_{j e t} / D\right) \exp \left(\alpha_{1}+\alpha_{2}\left[p_{j e t} / D\right]\right) R e^{0.6}$ $\alpha_{1}=-0.504-1.662(H / D)+0.233(H / D)^{2}$ $\alpha_{2}=-0.281+0.116(H / D)-0.017(H / D)^{2}$

For $H / D$ from 3.5 to $6, p_{j e t} / D$ from 4 to 8 , $N u_{0}=\left(p_{j e t} / D\right) \exp \left(\alpha_{1}+\alpha_{2}\left[p_{j e t} / D\right]\right) R e^{0.4}$

$\alpha_{1}=-2.627+0.546(H / D)-0.049(H / D)^{2}$

$\alpha_{2}=0.132-0.093(H / D)+0.008(H / D)^{2}$

For $H / D$ from 3.5 to $6, p_{\text {jet }} / D$ from 8 to 16 , $N u_{0}=\left(p_{\text {jet }} / D\right) \exp \left(\alpha_{1}+\alpha_{2}\left[p_{\text {jet }} / D\right]\right) R e^{0.5}$ $\alpha_{1}=-4.752+1.007(H / D)-0.103(H / D)^{2}$ $\alpha_{2}=0.229-0.132(H / D)+0.013(H / D)^{2}$

Impingement Device/Nozzle Type: Single Round Jet, Pipe and Tapered Nozzle

Source: Tawfek [104]

Range of validity: $r / D$ from 2 to $30, H / D$ from 6 to 58 , Re from 3,400 to 41,000

Equation (s):

$$
N u_{\text {avg }}=0.453 \operatorname{Pr}^{1 / 3} \operatorname{Re}^{0.691}(H / D)^{-0.22}(r / D)^{-0.38}
$$

Impingement Device/Nozzle Type: Single Round Jet, Pipe Nozzle

Source: Wen and Jang [105]

Range of validity: $H / D$ from 3 to $16, r / D$ from 0 to 7.14 , Re from 750 to 27,000

Equation ( $s$ ):

$$
N u_{\text {avg }}=0.442 \operatorname{Re}^{0.696} \operatorname{Pr}^{1 / 3}(H / D)^{-0.20}(r / D)^{-0.41}
$$


Table A. 2 provides an additional set of references with correlations and test data based on experimental studies of specific designs. Though the correlations may not be applicable to a wide variety of design points or conditions, the references may prove useful for performance prediction of specialized jet impingement device designs.

\section{B. Trends Within the Correlations}

By mapping out the correlation predictions as a function of independent design variables we can rapidly see what range of Nusselt numbers may be produced by a jet impingement device as well as the influences of design changes. Figure A.1 shows correlation predictions of area-averaged $N u$ for a

TABLE A.2

Supplemental Correlation and References, for Special Cases not Considered in Table A.1

\begin{tabular}{lcl}
\hline Source & \multicolumn{1}{c}{ Data/application } & \multicolumn{1}{c}{ Parameter range } \\
\hline Bartoli et al. [106] & Wide slot jet on small cylindrical & $1,500 \leqslant R e \leqslant 20,000$ \\
& target & $1.5 \leqslant H / B \leqslant 10$ \\
Gau and Lee [53] & Interaction of impinging jet and & $2,500 \leqslant R e \leqslant 11,000$ \\
& ribbed target surface & $2 \leqslant H / B \leqslant 16$ \\
Goldstein et al. [107] & Recovery and entrainment effects & $61,000 \leqslant R e \leqslant 124,000$ \\
& & $2 \leqslant H / D \leqslant 12$ \\
Goldstein and Franchett & Angled round jet on a flat target & $10,000 \leqslant R e \leqslant 35,000$ \\
[108] & & $4 \leqslant H / D \leqslant 10$ \\
Hargrave et al. [109] & Calculation of $N u_{0}$ as a function & $6837 \leqslant R e \leqslant 10742$ \\
& of $T u$ & $0.014 \leqslant T u \leqslant 0.256$ \\
Hoogendorn [20] & Calculation of $N u_{0}$ as a function & $2,000 \leqslant R e \leqslant 90,000$ \\
& of $T u$ & $2 \leqslant H / D \leqslant 8$ \\
Hrycak [110] & & $0.09 \leqslant T u \leqslant 0.20$ \\
Li and Garimella [111] & Array of round jets on concave & $25,000 \leqslant R e \leqslant 66,000$ \\
cylinder & $3 \leqslant H / D \leqslant 20$ \\
Sparrow and Alhomoud & Effect of $P r$ on $N u_{0}$ for various & $4,000 \leqslant R e \leqslant 23,000$ \\
Sparrow and Lovell [41] & fluids & $1 \leqslant H / D \leqslant 5$ \\
& Wide slot jet on small cylindrical & $5,000 \leqslant R e \leqslant 60,000$ \\
& target & $0.25 \leqslant B / d \leqslant 0.5$ \\
& Angled round jet on a flat target & $2,500 \leqslant R e \leqslant 10,000$ \\
& & $7 \leqslant H / D \leqslant 15$ \\
\hline
\end{tabular}


Averaged over $0<r / D<6, H / D=6, \operatorname{Pr}=0.71$

Dashed lines represent curves extrapolated beyond experimental data.

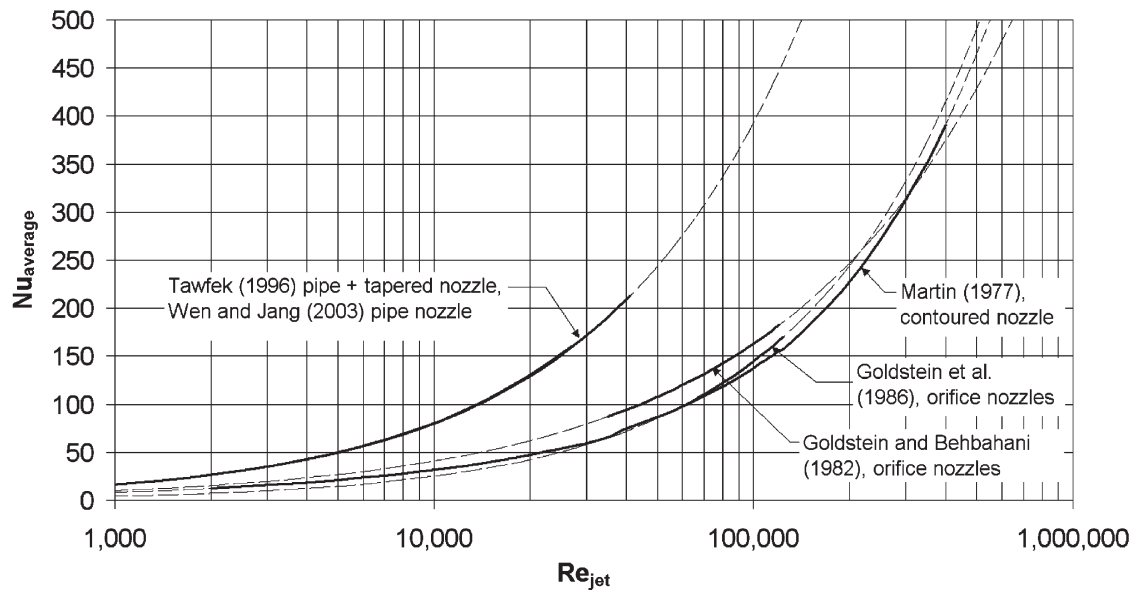

FIG. A.1. Sample comparison of correlations for single round jet impingement, $0<r / D<6$, $\mathrm{H} / \mathrm{D}=6$.

particular round-jet configuration with $H / D=6$, averaged over the span $0<r / D<6$. The large variation between correlations comes from the difference in nozzle types. The pipe nozzle correlations show a resulting $N u$ value two to three times higher than that of a contoured or orifice nozzle at the same $R e$, an effect resulting from higher initial turbulence in the fluid emerging from a pipe nozzle. In contrast, the orifice nozzles have little initial turbulence and rely more upon unsteady shear layer growth to promote turbulence an increase transfer rates. The apparent benefit of selecting a pipe nozzle design at this particular height and radial span must be weighed against the higher power required to drive fluid through a pipe nozzle.

By viewing the change in predicted $N u$ at a set value of $R e$ we can assess the relative importance of changes in the target radial span $\left(r_{\text {maximum }} / D\right)$ and nozzle height $(H / D)$ upon the area-averaged value of $N u$. Figure A.2 shows the dominant effect of $r / D$ over $H / D$, with Nusselt number plotted relative to a selected reference case at $H / D=6,0<r / D<5$. Though the opposing effects of jet deceleration and turbulence development are frequently studied and discussed, for a target of a set size at a fixed nozzle Reynolds number this effect is secondary to the choice of nozzle size expressed by the range of $r / D$.

Figure A.3 shows typical $N u$ values for heat transfer under an array of impinging jets with an inline jet pitch of $5 D$ using three correlations suitable 
Nusselt Number relative to reference case of $H / D=6,0<r / D<5$ from correlation equations of Martin (1977)

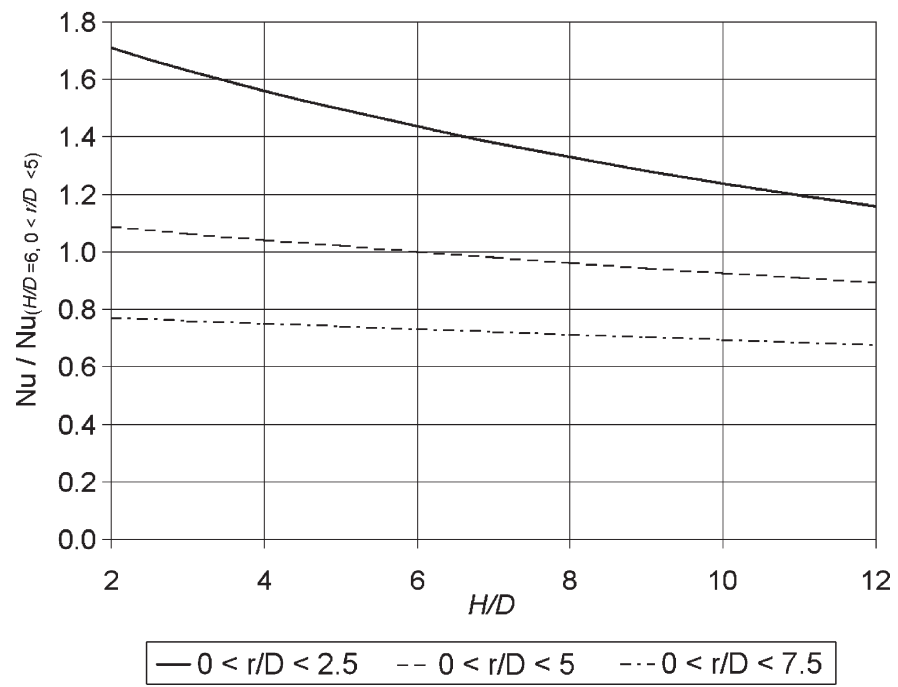

FIG. A.2. Influence of changes in jet height and target size at a set Reynolds number.

for three conditions. The correlation by Martin [2] includes the effect of jet interference and crossflow. The correlation by Florschuetz et al. [28] has been utilized based on a case with no crossflow penalty. The correlation by Huber and Viskanta [25] comes from an experiment using additional holes in the orifice plate to permit the exit of spent air. The predictions show a consistent trend, with the Huber and Viskanta data (based on a limited spent flow exit pathway) falling between the upper and lower brackets provided by the curves of Martin and the curves of Florschuetz et al. All three correlations show little degradation in $N u_{\text {avg }}$ with a $50 \%$ increase in $H / D$. For this case, the change in exit conditions between jet impingement without crossflow and jets in crossflow results in a degradation in $N u_{\text {avg }}$ of up to $25 \%$.

Figure A.4 shows the effect of changing jet pitch for a sample case with an array positioned at $H / D=3$. The influence of jet pitch on the average heat transfer rate is as important as that of Re. For this configuration it is seen that the heat transfer rate decreases as $p / D$ increases from $p / D=5$.

A similar effect is found for a design with a staggered jet array, as shown in Figure. A.5. As jet pitch $p_{j e t} / D$ increases beyond six, the transfer rate drops off, while for close jet spacing $\left(p_{\text {jet }} / D \leqslant 4\right)$ the detrimental effects of jet 


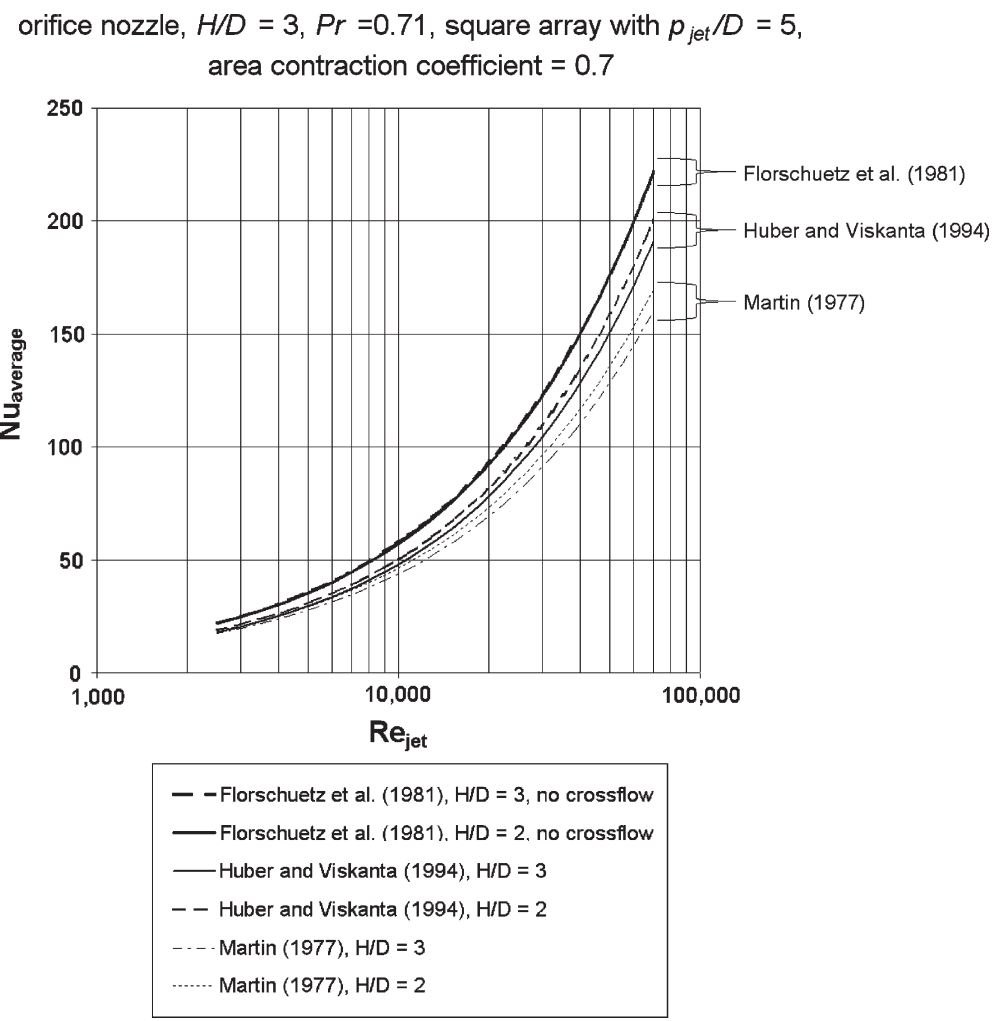

FIG. A.3. Sample comparison of correlations for inline array jet impingement, $p / D=5$.

interference are seen. The two sources used experiments with somewhat different setups. Florschuetz et al. used a large array of orifice nozzles emerging into a channel, confined on one side to control the direction of the spent flow. San and Lai measured the cooling effects under the central jet of a small array (five orifices), with the spent flow allowed to travel in all radial directions. In addition, the aspect ratio of the two tests differed, so a direct comparison may not be meaningful, but it is noteworthy that the two configurations showed similar trends with changes in $R e$ and $p_{j e t} / D$.

Figure A.6 shows the effect of changing jet height at various radial spans on the $N u$ value for single round jet impingement, based on the equations of Martin [2]. The detrimental effect of raising nozzle height becomes less significant when the transfer rate is averaged over a larger target (larger $r_{\text {maximum }}(D)$. 
orifice nozzle, Area contraction coefficient $=0.7, H / D=3, \operatorname{Pr}=0.71$, from correlation equations of Martin (1977)

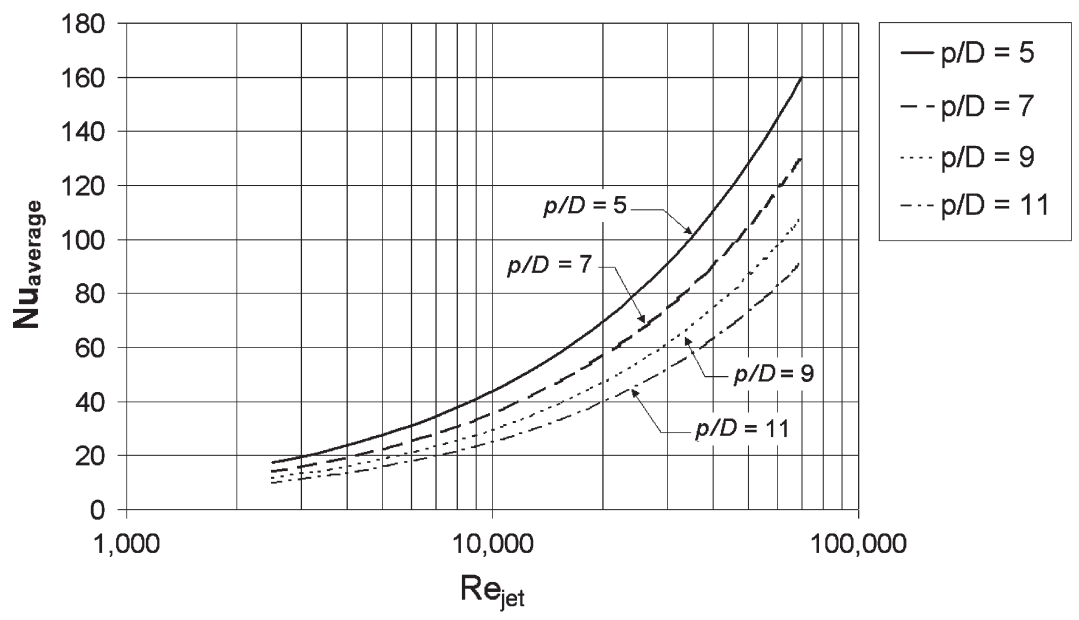

FIG. A.4. Effect of changing jet pitch on heat transfer rates for inline arrays of impinging jets.

orifice nozzle, $H / D=5, \operatorname{Pr}=0.71$,

from correlation of Florschuetz et al. (1981) and data of San and Lai (2001)

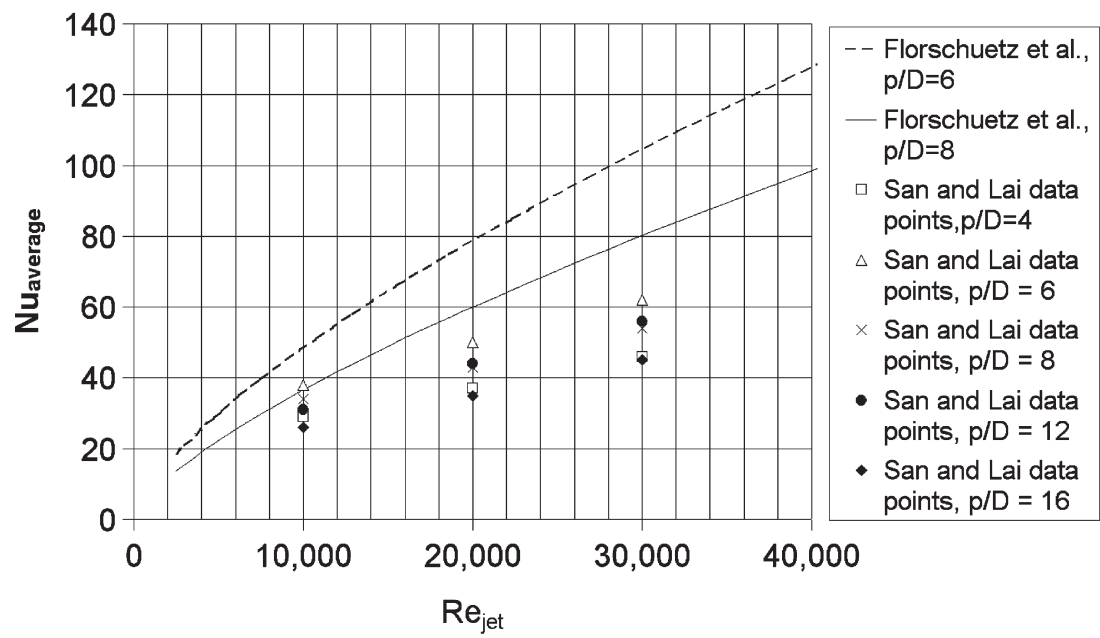

FIG.A.5. Effect of changing jet pitch for staggered arrays of impinging jets. 
Averaged over various radial ranges, various $H / D$, for $\operatorname{Pr}=0.71$

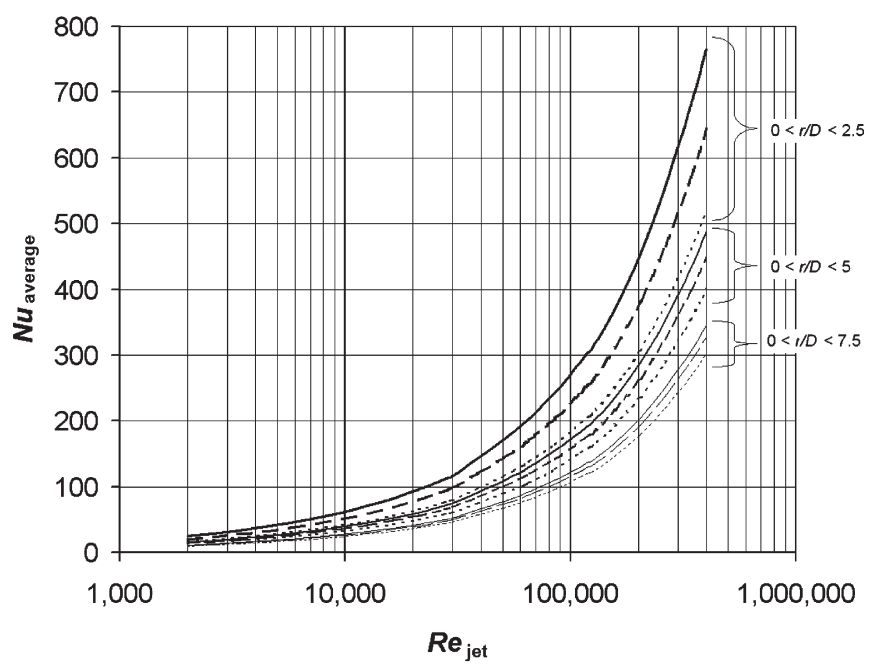

\begin{tabular}{cr|}
$-H / D=2,0<r / D<2.5$ & $--\cdot H / D=6,0<r / D<5$ \\
$--H / D=6,0<r / D<2.5$ & $\cdots . H / D=12,0<r / D<5$ \\
$\cdots \cdot H / D=12,0<r / D<2.5$ & $-H / D=2,0<r / D<7.5$ \\
$-H / D=2,0<r / D<5$ & $--H / D=6,0<r / D<7.5$ \\
$\cdots \cdots . . H / D=12,0<r / D<7.5$
\end{tabular}

FIG.A.6. Influence of jet nozzle height on $N u$ for targets of various radial span.

Figures A.7 and A.8 show the relative importance of $R e$, nondimensional target curvature $d / B$, and nozzle height $H / B$ for heat transfer on a convex curved cylinder. As with many other design variables, changes in nozzle size are coupled to all three of these non-dimensional variables. As $B$ increases to span more of the target, $H$ changes simultaneously, which also contributes to jet width. Heat transfer improves with submersion of more of the target surface in the stagnation zone, and less in the wall jet where separation may occur. Both $H / B$ and $d / B$ play an important role but are still not as influential as $R e$. A $100 \%$ increase in $R e$ results in a change in $N u$ of typically $50 \%$, while a $100 \%$ increase in $H / B$ gives a change in $N u$ of typically $10 \%$, and a $100 \%$ increase in $d / B$ changes $N u$ by approximately $30 \%$. The increase in $N u$ as $H / B$ grows to six shows the effect of the turbulence development in the growing shear layers at the edges of the free jet emerging. The decrease in $N u$ as $H / B$ grows to 10 illustrates the competing effect of velocity decay in the free jet. 


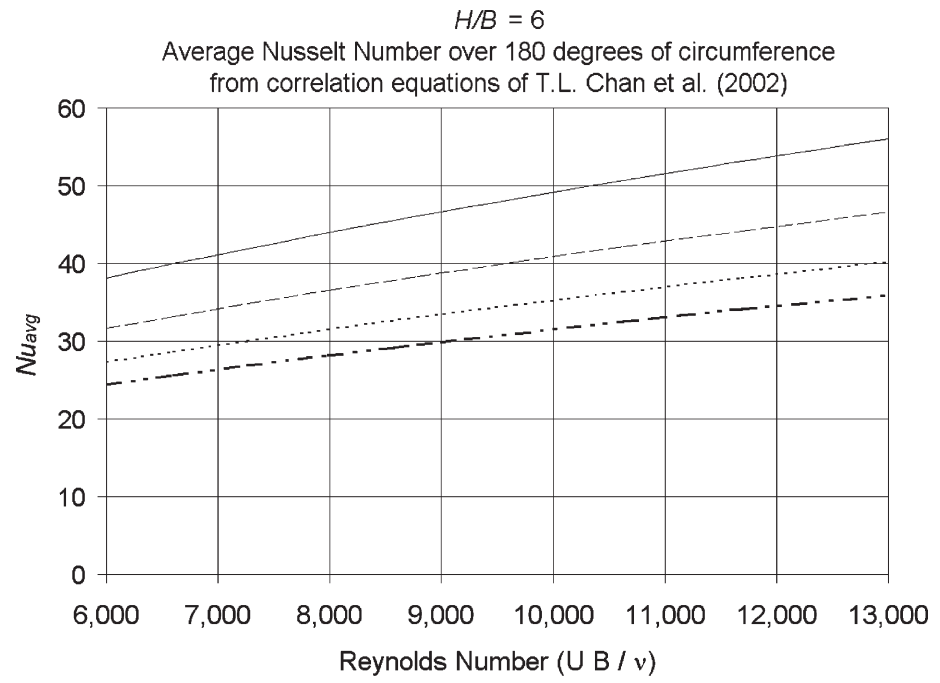

$$
\begin{aligned}
-d / B=2 & \cdots d d / B=6 \\
--d / B=4 & --d / B=8
\end{aligned}
$$

FIG. A.7. Slot jet impingement on a convex cylinder: influence of surface curvature.

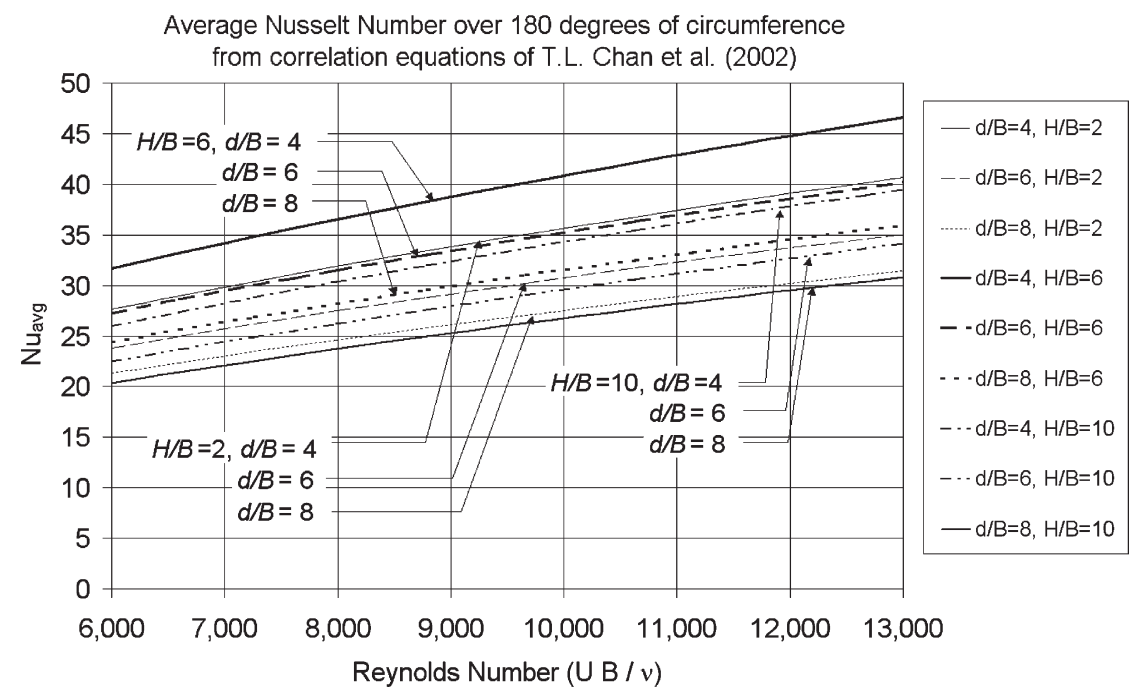

FIG. A.8. Slot jet impingement on a convex cylinder: Influence of curvature and jet height. 


\section{Nomenclature}

\begin{tabular}{|c|c|c|c|}
\hline $\begin{array}{l}A_{f} \\
b\end{array}$ & $\begin{array}{l}\text { target free area } \\
\text { correlation exponent, used in }\end{array}$ & Re & $\begin{array}{l}\text { Reynolds number }\left(=U_{0} D / v \text { for }\right. \\
\text { a jet) }\end{array}$ \\
\hline$B$ & $\begin{array}{l}N u \propto R e^{b} \\
\text { slot jet nozzle width }\end{array}$ & $R_{t}$ & $\begin{array}{l}\text { Turbulent Reynolds number } \\
\text { (Eqn 26) }\end{array}$ \\
\hline$C$ & mass concentration in fluid (with & $S_{i j}$ & strain rate tensor \\
\hline & subscript), or equation coefficient & $S c$ & Schmidt number $=$ fluid mass dif- \\
\hline$c^{\prime}{ }_{\varepsilon n}$ & empirical constants for $v^{2}-f$ model & & fusivity/fluid viscosity $=$ chemical \\
\hline$c_{n}$ & empirical constants for turbulence & & diffusivity/fluid viscosity \\
\hline & model $\left(c_{1}, c_{\varepsilon}, c_{\mu}, c_{\theta}, c_{w}\right)$ & $S h$ & Sherwood number \\
\hline$c_{p}$ & specific heat of fluid & $t$ & time \\
\hline$C_{0 \text { jet }}$ & jet mass concentration & $T$ & temperature \\
\hline$C_{n}$ & empirical constants for $v^{2}-f$ model & $T_{\text {scale }}$ & time scale \\
\hline$C_{\text {wall }}$ & wall surface concentration & $T_{0 \text { jet }}$ & jet adiabatic wall temperature, \\
\hline$C_{\mu}$ & turbulence model constant for & & exiting nozzle \\
\hline & rbulent viscosity & $T_{f}$ & far-field fluid temperature \\
\hline$C D_{k \omega}$ & cross-diffusion term & $T_{s}$ & wall surface temperature \\
\hline & target diameter (twice target radius & $T_{\text {wall }}$ & wall surface temperature \\
\hline & of $\mathrm{cl}$ & $T u$ & turbulence intensity (with \\
\hline$D$ & nozzle diameter & & subscript), or position along wall \\
\hline$D_{h}$ & hydraulic diameter of nozzle & & surface \\
\hline$D_{i}$ & mass diffusivity constant & $U$ or $u$ & fluid velocity component \\
\hline$f$ & nozzle area or $v^{2} f$ model & & $\begin{array}{l}\text { general velocity vector } \\
\text { jet initial speed, average }\end{array}$ \\
\hline$f_{\varepsilon}$ & el function & $v$ & fluid \\
\hline$f_{\mu}$ & $k-\varepsilon$ model function & $v^{2}$ & streamwise-norm \\
\hline$f_{\text {wall }}$ & $v^{2} f \mathrm{~m}$ & & ance (from $v^{2}-f$ r \\
\hline$F_{1}$ & wall blending function & $x$ & coordinate direction (with \\
\hline G & low per unit of target area & & ript), or position along wall \\
\hline$h$ & ive heat transfer coefficient & & surface \\
\hline$H$ & $\begin{array}{l}\text { nozzle-to-target spacing (nozzle } \\
\text { height) }\end{array}$ & $y$ & $\begin{array}{l}\text { distance from wall for turbulence } \\
\text { model }\end{array}$ \\
\hline$k_{c}$ & fluid thermal conductivity & $y^{+}$ & nondimensional distance from wall \\
\hline$k$ & turbulent kinetic energy & $Y c$ & Yap correction (used with $k-\varepsilon$ \\
\hline$k_{i}$ & mass transfer coefficient & & model) \\
\hline$L_{\text {scal }}$ & length scale & $z$ & axial position or height, measured \\
\hline$M$ & Mach numbe & & off of target surface (distance from \\
\hline$\hat{n}$ & unit vector & & wall) \\
\hline$N u$ & Nusselt number & \multirow{2}{*}{\multicolumn{2}{|c|}{ GREeK LetTERs }} \\
\hline$N u_{0}$ & Nusselt number at stagnation & & \\
\hline & & $\alpha$ & tu \\
\hline$p$ & fluid pressure & $\beta$ & turbulence model constant \\
\hline$p_{\text {jet }}$ & nter-to-center distance) & $\delta_{i j}$ & identity tensor \\
\hline $\mathrm{Pr}$ & $\begin{array}{l}\text { Prandtl number = fluid thermal } \\
\text { diffusivity/fluid viscosity }\end{array}$ & $\varepsilon$ & $\begin{array}{l}\text { turbulent kinetic energy dissi- } \\
\text { pation rate }\end{array}$ \\
\hline$Q$ & volumetric flow rate & $\tilde{\varepsilon}$ & isotropic turbulent kinetic energy \\
\hline$q^{\prime \prime}$ & & & dissipation rate \\
\hline$r$ & $\begin{array}{l}\text { radial position, measured from jet } \\
\text { axis }\end{array}$ & $\theta$ & $\begin{array}{l}\text { general scalar quantity such as } \\
\text { temperature }\end{array}$ \\
\hline
\end{tabular}




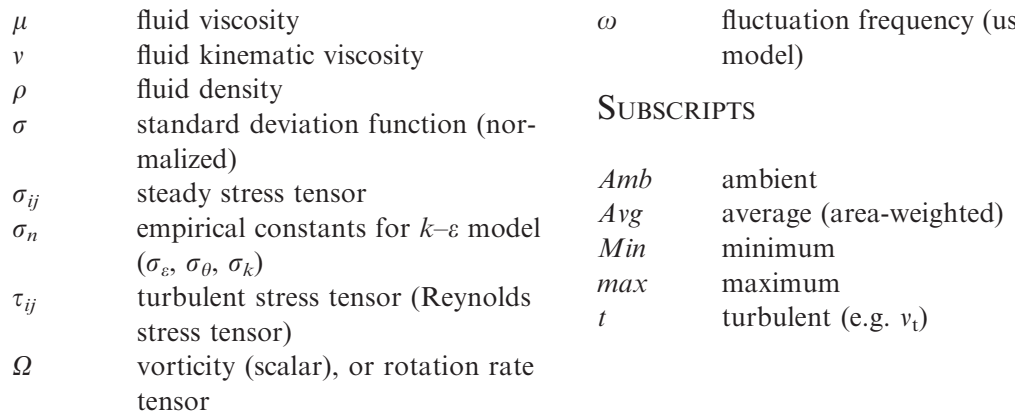

\section{References}

1. Ferrari, J., Lior, N., and Slycke, J. (2003). An evaluation of gas quenching of steel rings by multiple-jet impingement. J. Mater. Process. Technol. 136, 190-201.

2. Martin, H. (1977). Heat and mass transfer between impinging gas jets and solid surfaces. Adv. Heat Transfer 13, 1-60.

3. Jambunathan, K., Lai, E., Moss, M. A., and Button, B. L. (1992). A review of heat transfer data for single circular jet impingement. Int. J. Heat Fluid Flow 13, 106-115.

4. Donaldson, C. D. and Snedeker, R. S. (1971). A study of free jet impingement. Part 1. Mean properties of free and impinging jets,. J. Fluid Mech. 45, 281-319.

5. Viskanta, R. (1993). Heat transfer to impinging isothermal gas and flame jets. Exp. Thermal Fluid Sci. 6, 111-134.

6. Zuckerman, N. and Lior, N. (2005). Impingement heat transfer: Correlations and numerical modeling. J. Heat Transfer 127, 544-552.

7. Han, J.-C., Dutta, S., and Ekkad, S. (2000). "Gas Turbine Heat Transfer and Cooling Technology". Taylor \& Francis, New York.

8. Taniguchi, H., Miyamae, S., Arai, N., and Lior, N. (2000). Power generation analysis for high temperature gas turbine in thermodynamic process. AIAA J. Propul. Power 16, $557-561$.

9. Maurel, S. and Solliec, C. (2001). A turbulent plane jet impinging nearby and far from a flat plate. Exp. Fluids 31, 687-696.

10. Goldstein, R. J., Behbahani, A. I., and Heppelmann, K. K. (1986). Streamwise distribution of the recovery factor and the local heat transfer coefficient to an impinging circular air jet. Int. J. Heat Mass Transfer 29, 1227-1235.

11. Kim, B. G., Yu, M. S., Cho, Y. I., and Cho, H. H. (2002). Distributions of recovery temperature on flat plate by underexpanded supersonic impinging jet. J. Thermophys. Heat Transfer 16, 425-431.

12. Lee, J. and Lee, S. (2000). The effect of nozzle configuration on stagnation region heat transfer enhancement of axisymmetric jet impingement. Int. J. Heat Mass Transfer 43, 3497-3509.

13. Kreith, F., Goswami, D. Y. (2005). "The CRC Handbook of Mechanical Engineering". Section 3, CRC Press, Boca Raton, FL.

14. Saleh, J. M. (2002). "Fluid Flow Handbook". McGraw-Hill, New York.

15. Ward-Smith, A. J. (1971). "Pressure Losses in Ducted Flows". Butterworths, London.

16. Gan, G. and Riffat, S. B. (1997). Pressure loss characteristics of orifice and perforated plates. Exp. Thermal Fluid Sci. 14, 160-165. 
17. Rahimi, M., Owen, I., and Mistry, J. (2003). Heat transfer between an under-expanded jet and a cylindrical surface. Int. J. Heat Mass Transfer 46, 3135-3412.

18. Peyret, R. (1996). "Handbook of Computational Fluid Mechanics". Academic Press, San Diego, CA.

19. Gao, S. and Voke, P. R. (1995). Large-eddy simulation of turbulent heat transport in enclosed impinging jets. Int. J. Heat Fluid Flow 16, 349-356.

20. Hoogendorn, C. J. (1977). The effect of turbulence on heat transfer at a stagnation point. Int. J. Heat Mass Transfer 20, 1333-1338.

21. Abe, K. and Suga, K. (2001). Large eddy simulation of passive scalar in complex turbulence with flow impingement and flow separation. Heat Transfer - Asian Res. 30, 402-418.

22. Cooper, D., Jackson, C., Launder, B. E., and Liao, G. X. (1993). Impinging jet studies for turbulence model assessment - I. Flow-field experiments,. Int. J. Heat Mass Transfer 36, 2675-2684.

23. Gardon, R. and Akfirat, J. C. (1965). The role of turbulence in determining the heattransfer characteristics of impinging jets. Int. J. Heat Mass Transfer 8, 1261-1272.

24. Chung, Y. M. and Luo, K. H. (2002). Unsteady heat transfer analysis of an impinging jet. ASME J. Heat Transfer 124, 1039-1048.

25. Behnia, M., Parneix, S., Shabany, Y., and Durbin, P. A. (1999). Numerical study of turbulent heat transfer in confined and unconfined impinging jets. Int. J. Heat Fluid Flow 20, 1-9.

26. Narayanan, V., Seyed-Yagoobi, J., and Page, R. H. (2004). An experimental study of fluid mechanics and heat transfer in and impinging slot jet flow. Int. J. Heat Mass Transfer 47, $1827-1845$.

27. San, J. Y. and Lai, M. (2001). Optimum jet-to-jet spacing of heat transfer for staggered arrays of impinging air jets. Int. J. Heat Mass Transfer 44, 3997-4007.

28. Slayzak, S. J., Viskanta, R., and Incropera, F. P. (1994). Effects of interaction between adjacent free surface planar jets on local heat transfer from the impingement surface. Int. J. Heat Mass Transfer 37, 269-282.

29. Aldabbagh, L. B. Y. and Sezai, I. (2002). Numerical simulation of three-dimensional laminar multiple impinging square jets. Int. J. Heat Fluid Flow 23, 509-518.

30. Huber, A. M. and Viskanta, R. (1994). Effect of jet-jet spacing on convective heat transfer to confined, impinging arrays of axisymmetric jets. Int. J. Heat Mass Transfer 37, 2859-2869.

31. A. Chambers, D. R. H. Gillespie, P. T. Ireland, G. M. Dailey, (November 2003). Cooling performance of a narrow impingement channel including the introduction of cross flow upstream of the first hole. In: Proceedings of IMECE'03, 2003 ASME International Mechanical Engineering Congress, Washington, DC, November 15-12, 2003, IMECE2003-43975.

32. Florschuetz, L. W., Berry, R. A., and Metzger, D. E. (1980). Periodic streamwise variations of heat transfer coefficients for inline and staggered arrays of circular jets with crossflow of spent air. J. Heat Transfer 102, 132-137.

33. Florschuetz, L. W., Truman, C. R., and Metzger, D. E. (1981). Streamwise flow and heat transfer distributions for jet array impingement with crossflow. J. Heat Transfer 103, $337-342$.

34. Florschuetz, L. W., Metzger, D. E., and Su, C. C. (1984). Heat transfer characteristics for jet array impingement with initial crossflow. J. Heat Transfer 106, 34-41.

35. Chattopadhyay, H. and Saha, S. K. (2003). Turbulent flow and heat transfer from a slot jet impinging on a moving plate. Int. J. Heat Fluid Flow 24, 685-697.

36. Bilen, K., Bakirci, K., Yapici, S., and Yavuz, T. (2002). Heat transfer from an impinging plate jet. Int. J. Energy Res. 26, 305-320. 
37. Lee, D. H., Won, S. E., Kim, Y. T., and Chung, Y. S. (2002). Turbulent heat transfer from a flat surface to a swirling round impinging jet. Int. J. Heat Mass Transfer 45, 223-227.

38. Nozaki, A., Igarashi, Y., and Hishida, K. (2003). Heat transfer mechanism of a swirling impinging jet in a stagnation region. Heat Transfer - Asian Res 32, 663-673.

39. Wen, M.-Y. (2005). Flow structures and heat transfer of swirling jet impinging on a flat surface with micro-vibrations. Int. J. Heat Mass Transfer 48, 545-560.

40. Tawfek, A. A. (2002). Heat transfer studies of the oblique impingement of round jets upon a curved surface. Heat Mass Transfer 38, 467-475.

41. Sparrow, E. M. and Lovell, B. J. (1980). Heat transfer characteristics of an obliquely impinging circular jet. ASME J. Heat Transfer 102, 202-209.

42. Bart, G. C. J., van Ijzerloo, A. J., Geers, L. F. G., Hoek, L., and Hanjalic, K. (2002). Heat transfer of phase-locked modulated impinging-jet arrays. Exp. Thermal Fluid Sci. 25, 299-304.

43. Göppert, S., Gürtler, T., Mocikat, H., and Herwig, H. (2004). Heat transfer under a precessing jet: Effects of unsteady jet impingement. Int. J. Heat Mass Transfer 47, 2795-2806.

44. Hwang, S. D., Lee, C. H., and Cho, H. H. (2001). Heat transfer and flow structures in axisymmetric impinging jet controlled by vortex pairing. Int. J. Heat Fluid Flow 22, 293-300.

45. Ichimiya, K. (2003). Heat transfer characteristics of an annular turbulent impinging jet with a confined wall measured by thermosensitive liquid crystal. Heat Mass Transfer 39, 545-551.

46. Gau, C. and Chung, C. M. (1991). Surface curvature effect on slot-air-jet impingement cooling flow and heat transfer process. J. Heat Transfer 113, 858-864.

47. Fleischer, A. S., Kramer, K., and Goldstein, R. J. (2001). Dynamics of the vortex structure of a jet impinging on a convex surface. Exp. Thermal Fluid Sci. 24, 169-175.

48. Gori, F. and Bossi, L. (2003). Optimal slot height in the jet cooling of a circular cylinder. Appl. Thermal Eng. 23, 859-870.

49. McDaniel, C. S. and Webb, B. W. (2000). Slot jet impingement heat transfer from circular cylinders. Int. J. Heat Mass Transfer 23, 1975-1985.

50. Cornaro, C., Fleischer, A. S., and Goldstein, R. J. (1999). Flow visualization of a round jet impinging on cylindrical surfaces. Exp. Thermal Fluid Sci. 20, 66-78.

51. Kayansayan, N. and Kucuka, S. (2001). Impingement cooling of a semi-cylindrical concave channel by confined slot-air-jet. Exp. Thermal Fluid Sci. 25, 383-396.

52. Taslim, M. E., Setayeshgar, L., and Spring, S. D. (2001). An experimental evaluation of advanced leading edge impingement cooling concepts. ASME J. Turbomachinery 123, $147-153$.

53. Cau, C. and Lee, C. C. (1992). Impingement cooling flow structure and heat transfer along rib-roughened walls. Int. J. Heat Mass Transfer 35, 3009-3020.

54. Rhee, D., Yoon, P., and Cho, H. H. (2003). Local heat/mass transfer and flow characteristics of array impinging jets with effusion holes ejecting spent air. Int. J. Heat Mass Transfer 46, 1049-1061.

55. Li, X., Gaddis, J. L., and Wang, T. (2001). Modeling of heat transfer in a mist/steam impinging jet. ASME J. Heat Transfer 123, 1086-1092.

56. Yokomine, T., Shimizu, A., Saitoh, A., and Higa, K. (2002). Heat transfer of multiple impinging jets with gas-solid suspensions. Exp. Thermal Fluid Sci. 26, 617-626.

57. Yoshida, H., Suenaga, K., and Echigo, R. (1990). Turbulence structure and heat transfer of a two-dimensional impinging jet with gas-solid suspensions. Int. J. Heat Mass Transfer 33, 859-867. 
58. Malikov, G. K., Lobanov, D. L., Malikov, K. Y., Lisienko, V. G., Viskanta, R., and Fedorov, A. G. (2001). Direct flame impingement heating for rapid thermal materials processing. Int. J. Heat Mass Transfer 44, 1751-1758.

59. Dong, L. L., Leung, C. W., and Cheung, C. S. (2004). Heat transfer and wall pressure characteristics of a twin premixed butane/air flame jets. Int. J. Heat Mass Transfer 47, 489-500.

60. Baukal, C. E. and Gebhart, B. (1996). A review of empirical flame impingement heat transfer correlations. Int. J. Heat Fluid Flow 17, 386-396.

61. Baukal, C. E. and Gebhart, B. (1996). A review of semi-analytical solutions for flame impingement heat transfer. Int. J. Heat Mass Transfer 39, 2989-3002.

62. Ashforth-Frost, S., Jambunathan, K., and Whitney, C. F. (1997). Velocity and turbulence characteristics of a semiconfined orthogonally impinging slot jet. Exp. Thermal Fluid Sci. 14, 60-67.

63. Chan, T. L., Leung, C. W., Jambunathan, K. J., Ashforth-Frost, S., Zhou, Y., and Liu, M. H. (2002). Heat transfer characteristics of a slot jet impinging on a semi-circular convex surface. Int. J. Heat Mass Transfer 45, 993-1006.

64. Colucci, D. W. and Viskanta, R. (1996). Effect of nozzle geometry on local convective heat transfer to a confined impinging air jet. Exp. Thermal Fluid Sci. 13, 71-80.

65. Wiberg, R. and Lior, N. (2004). Errors in thermochromic liquid crystal thermometry. Rev. Sci. Instrum. 75(9), 2985-2994.

66. Wiberg, R., Muhammad-Klingmann, B., Ferrari, J., and Lior, N. (2000). Thermochromic coatings help characterize gas quenching. ASM Int. Heat Treat. Prog. 158(4), 37-40.

67. Burmeister, L. C. (1993). "Convective Heat Transfer". Wiley, New York, NY.

68. Kang, S. H. and Greif, R. (1992). Flow and heat transfer to a circular cylinder with a hot impinging jet. Int. J. Heat Mass Transfer 35, 2173-2183.

69. Polat, S., Huang, B., Mujumdar, A. S., and Douglas, W. J. M. (1989). Numerical flow and heat transfer under impinging jets: A review. Ann. Rev. Fluid Mech. Heat Transfer 2, 157-197.

70. Beaubert, F. and Viazzo, S. (2002). Large eddy simulation of a plane impinging jet. C. $R$. Mecanique 330, 803-810.

71. Hällqvist, T. (2003). "Numerical study of impinging jets with heat transfer, Licentiate Thesis". Royal Institute of Technology, Stockholm, Sweden, Universitetsservice US AB Stockholm. ISSN 0348-467X.

72. Olsson, M. and Fuchs, L. (1998). Large eddy simulations of a forced semiconfined circular impinging jet. Phys. Fluids 10(2), 476-486.

73. Cziesla, T., Biswas, G., Chattopadhyay, H., and Mitra, N. K. (2001). Large-eddy simulation of flow and heat transfer in an impinging slot jet. Int. J. Heat Fluid Flow 22, 500-508.

74. Chen, C.-J. and Jaw, S.-Y. (1998). "Fundamentals of Turbulence Modeling. Taylor and Francis". Washington, DC.

75. Craft, T. J., Graham, L. J. W., and Launder, B. E. (1993). Impinging jet studies for turbulence model assessment - II. An examination of the performance of four turbulence models. Int. J. Heat Mass Transfer 36, 2685-2697.

76. Bouainouche, M., Bourabaa, N., and Desmet, B. (1997). Numerical study of the wall shear stress produced by the impingement of a plane turbulent jet on a plate. Int. J. Numer. Methods Heat Fluid Flow 7, 548-564.

77. Esch, T., Menter, F., and Vieser, W. (2003). Heat transfer predictions based on twoequation turbulence models. In "The 6th ASME-JSME Thermal Engineering Joint Conference, March 16-20, 2003," TED-AJ03-542. 
78. Heyerichs, K. and Pollard, A. (1996). Heat transfer in separated and impinging turbulent flows. Int. J. Heat Mass Transfer 39, 2385-2400.

79. Craft, T. J., Launder, B. E., and Suga, K. (1996). Development and application of a cubic eddy-viscosity model of turbulence. Int. J. Heat Fluid Flow 17, 108-115.

80. Turgeon, E. and Pelletier, D. (2001). Verification and validation of adaptive finite element method for impingement heat transfer. J. Thermophys. Heat Transfer 15, 284-292.

81. Merci, B., Vierendeels, I., DeLange, C., and Dick, E. (2003). Numerical simulation of heat transfer of turbulent impinging jets with two-equation turbulence models. Int. J. Numer. Methods Heat Fluid Flow 13, 110-132.

82. Souris, N., Liakos, H., Founti, M., Palyvos, J., and Markatos, N. (2002). Study of impinging turbulent jet flows using the isotropic low-reynolds number and the algebraic stress methods. Comput. Mech. 28, 381-389.

83. Tzeng, P. Y., Soong, C. Y., and Hsieh, C. D. (1999). Numerical investigation of heat transfer under confined impinging turbulent slot jets. Numerical Heat Transfer, Part A 35, 903-924.

84. Abe, K., Kondoh, T., and Nagano, Y. (1994). A new turbulence model for predicting fluid flow and heat transfer in separating and reattaching flows - I: Flow field calculations. Int. J. Heat Mass Transfer 37, 139-151.

85. Hayase, T., Humphrey, J. A. C., and Greif, R. (1992). A consistently formulated quick scheme for fast and stable convergence using finite-volume iterative calculation procedures. J. Comput. Phys. 98, 108-118.

86. Heck, U., Fritsching, K., and Bauckhage, K. (2001). Fluid flow and heat transfer in gas jet quenching of a cylinder. Int. J. Numer. Methods Heat Fluid Flow 11, 36-49.

87. Wilcox, D. C. (2002). "Turbulence Modeling For CFD," 2nd edn. DCW Industries, La Cañada, CA.

88. Park, T. H., Choi, H. G., Yoo, J. Y., and Kim, S. J. (2003). Streamline upwind numerical simulation of two-dimensional confined impinging slot jets. Int. J. Heat Mass Transfer 46, 251-262.

89. Chen, Q. and Modi, V. (1999). Mass transfer in turbulent impinging slot jets. Int. J. Heat Mass Transfer 42, 873-887.

90. Shih, T.-H., Liou, W. W., Shabbir, A., Yang, Z., and Zhu, J. (1995). A new $k-\varepsilon$ eddyviscosity model for high reynolds number turbulent flows - model development and validation. Comput. Fluids 24(3), 227-238.

91. Abdon, A. and Sunden, B. (2001). Numerical investigation of impingement heat transfer using linear and nonlinear two-equation turbulence models. Numer. Heat Transfer, Pt. A 40, 563-578.

92. Park, T. S. and Sung, H. J. (2001). Development of a near-wall turbulence model and application to jet impingement heat transfer. Int. J. Heat Fluid Flow 22, 10-18.

93. Funazaki, K. and Hachiya, K. (2003). Systematic numerical studies on heat transfer and aerodynamic characteristics of impingement cooling devices combined with pins, In "Proceedings of ASME Turbo Expo 2003, June 16-19, Atlanta, GA, USA".

94. Demuren, A. O. (1994). Calculations of 3D impinging jets in crossflow with Reynolds stress models. In "Heat Transfer in Turbomachinery" (R.J. Goldstein, D.E. Metzger and A.I. Leontiev, eds.), pp. 527-540. Begell House, Inc., New York.

95. Shi, Y., Ray, M. B., and Mujumdar, A. S. (2002). Computational study of impingement heat transfer under a turbulent slot jet. Ind. Eng. Chem. Res. 41, 4643-4651.

96. Behnia, M., Parneix, S., and Durbin, P. A. (1998). Prediction of heat transfer in an axisymmetric turbulent jet impinging on a flat plate. Int. J. Heat Mass Transfer 41, $1845-1855$. 
97. Thielen, L., Jonker, H. J. J., and Hanjalic, K. (2003). Symmetry breaking of flow and heat transfer in multiple impinging jets. Int. J. Heat Fluid Flow 24, 444-453.

98. Menter, F. R. (1993). Zonal two equation k- $\omega$ turbulence models for aerodynamic flows. In "AIAA 24th Fluid Dynamics Conference, July 6-9, 1993, Orlando, FL". AIAA93-2906.

99. Goldstein, R. J. and Seol, W. S. (1991). Heat transfer to a row of impinging circular air jets including the effect of entrainment. Int. J. Heat Mass Transfer 34, 2133-2147.

100. Goldstein, R. J. and Behbahani, A. I. (1982). Impingement of a circular jet with and without crossflow. Int. J. Heat Mass Transfer 25, 1377-1382.

101. Huang, L. and El-Genk, M. (1994). Heat transfer of an impinging jet on a flat surface. Int. J. Heat Mass Transfer 37, 1915-1923.

102. Lytle, D. and Webb, B. W. (1994). Air jet impingement heat transfer at low nozzle-plate spacings. Int. J. Heat Mass Transfer 37, 1687-1697.

103. Mohanty, A. K. and Tawfek, A. A. (1993). Heat transfer due to a round jet impinging normal to a flat surface. Int. J. Heat Mass Transfer 36, 1639-1647.

104. Tawfek, A. A. (1996). Heat transfer and pressure distributions of an impinging jet on a flat surface. Heat Mass Transfer 32, 49-54.

105. Wen, M.-Y. and Jang, K.-J. (2003). An impingement cooling on a flat surface by using circular jet with longitudinal swirling strips. Int. J. Heat Mass Transfer 46, 4657-4667.

106. Bartoli, C., Di Marco, P., and Faggiani, S. (1993). Impingement heat transfer at a circular cylinder due to a submerged slot jet of water. Exp. Thermal Fluid Sci. 7, 279-286.

107. Goldstein, R. J., Sobolik, K. A., and Seol, W. S. (1990). Effect of entrainment on the heat transfer to a heated circular air jet impinging on a flat surface. ASME J. Heat Transfer 112, 608-611.

108. Goldstein, R. J. and Franchett, M. E. (1988). Heat transfer from a flat surface to an oblique impinging jet. ASME J. Heat Transfer 110, 84-90.

109. Hargrave, G. K., Fairweather, M., and Kilham, J. K. (1986). Turbulence enhancement of stagnation point heat transfer on a circular cylinder. Int. J. Heat Fluid Flow 7, 132-138.

110. Hrycak, P. (1981). Heat transfer from a row of impinging jet to concave cylindrical surfaces. Int. J. Heat Mass Transfer 24, 407-419.

111. Li, C.-Y. and Garimella, S. V. (2001). Prandtl-number effects and generalized correlations for confined and submerged jet impingement. Int. J. Heat Mass Transfer 44, 3471-3480.

112. Sparrow, E. M. and Alhomoud, A. (1984). Impingement heat transfer at a circular cylinder due to an offset or non-offset slot jet. Int. J. Heat Mass Transfer 27, 2297-2306. 